SGM Special Lecture

\section{Fleming Prize \\ Lecture 2006}

Delivered at the 158th meeting of the SGM, 5 April 2006

Correspondence

Frank Sargent

f.sargent@uea.ac.uk

\title{
Constructing the wonders of the bacterial world: biosynthesis of complex enzymes
}

\author{
Frank Sargent \\ Centre for Metalloprotein Spectroscopy and Biology, School of Biological Sciences, University \\ of East Anglia, Norwich NR4 7TJ, UK
}

\begin{abstract}
The prokaryotic cytoplasmic membrane not only maintains cell integrity and forms a barrier between the cell and its outside environment, but is also the location for essential biochemical processes. Microbial model systems provide excellent bases for the study of fundamental problems in membrane biology including signal transduction, chemotaxis, solute transport and, as will be the topic of this review, energy metabolism. Bacterial respiration requires a diverse array of complex, multi-subunit, cofactor-containing redox enzymes, many of which are embedded within, or located on the extracellular side of, the membrane. The biosynthesis of these enzymes therefore requires carefully controlled expression, assembly, targeting and transport processes. Here, focusing on the molybdenum-containing respiratory enzymes central to anaerobic respiration in Escherichia coli, recent descriptions of a chaperone-mediated 'proofreading' system involved in coordinating assembly and export of complex extracellular enzymes will be discussed. The paradigm proofreading chaperones are members of a large group of proteins known as the TorD family, and recent research in this area highlights common principles that underpin biosynthesis of both exported and non-exported respiratory enzymes.
\end{abstract}

\section{Introduction}

Prokaryotes are renowned for their metabolic adaptability and diversity. Many prokaryotes can switch with relative ease between aerobic and anaerobic conditions, for example, or can improvise the use of inorganic compounds, such as hydrogen or sulfur, to form respiratory chains under even the most extreme environmental conditions. This remarkable respiratory adaptability is thanks to an elaborate bank of complex, multi-subunit, cofactor-containing redox enzymes, ready and waiting to be called upon (Richardson, 2000).

The well-studied Gram-negative $\gamma$-proteobacterium Escherichia coli is a facultative anaerobe and so is typically very flexible in its use of respiratory electron donors and acceptors (Fig. 1). In E. coli, respiratory chains are relatively short, with reducing power being shuttled between only two enzymes by lipid-soluble quinones (Fig. 1), namely ubiquinone, menaquinone and demethylmenaquinone (Soballe \& Poole, 1999). The generation of energy by respiratory electron-transfer chains involves the ionically sealed cytoplasmic membrane and, in the context of this particular review, it is most notable that respiratory enzymes, or at least their catalytic domains, can be located on either side of the lipid bilayer (Fig. 1). Indeed, in terms of physiological function, the subcellular localization of all of these enzymes is absolutely critical. Some substrates, for example trimethylamine $N$-oxide (TMAO) and nicotinamide adenine dinucleotide $(\mathrm{NADH})$, are membrane impermeable and therefore must be metabolized on one particular side of the membrane. More important, perhaps, is the application of the 'redox loop mechanism' by respiratory chains to develop a transmembrane proton-motive force (Mitchell, 1961; Mitchell \& Moyle, 1967; recently reviewed by Jormakka et al., 2003). Redox loops are generated by membrane-associated respiratory enzymes in which the substrate and quinone/quinol-binding sites are juxtaposed on opposite sides of the lipid bilayer. Separation of the active sites in this way allows protons to be released, and taken up, on opposite sides of the membrane and thus contribute to a proton electrochemical gradient. Not all quinone/quinoldependent respiratory systems are so 'electrogenic', but in $E$. coli the activities of two such enzymes are coupled to great effect under anaerobic conditions in the presence of nitrate (Enoch \& Lester, 1975; Jormakka et al., 2003). Under these conditions formate oxidation in the periplasm is coupled, through a quinone mediator, to nitrate reduction in the cytoplasm. The formate dehydrogenase enzyme (often termed formate dehydrogenase- $\mathrm{N}$ as it is nitrate-inducible) is composed of three polypeptides, FdnG, FdnH and FdnI, with the formate-oxidation site being located on the FdnG subunit at the periplasmic side of the membrane (Jormakka et al., 2002, 2003). The quinone-reducing site is located on $\mathrm{FdnI}$ at the cytoplasmic side of the membrane (Jormakka et al., 2002, 2003). The topology and location of the substrate-binding sites are unequivocal since the 3D crystal structure of the intact complex has been solved to $1.6 \AA$ 


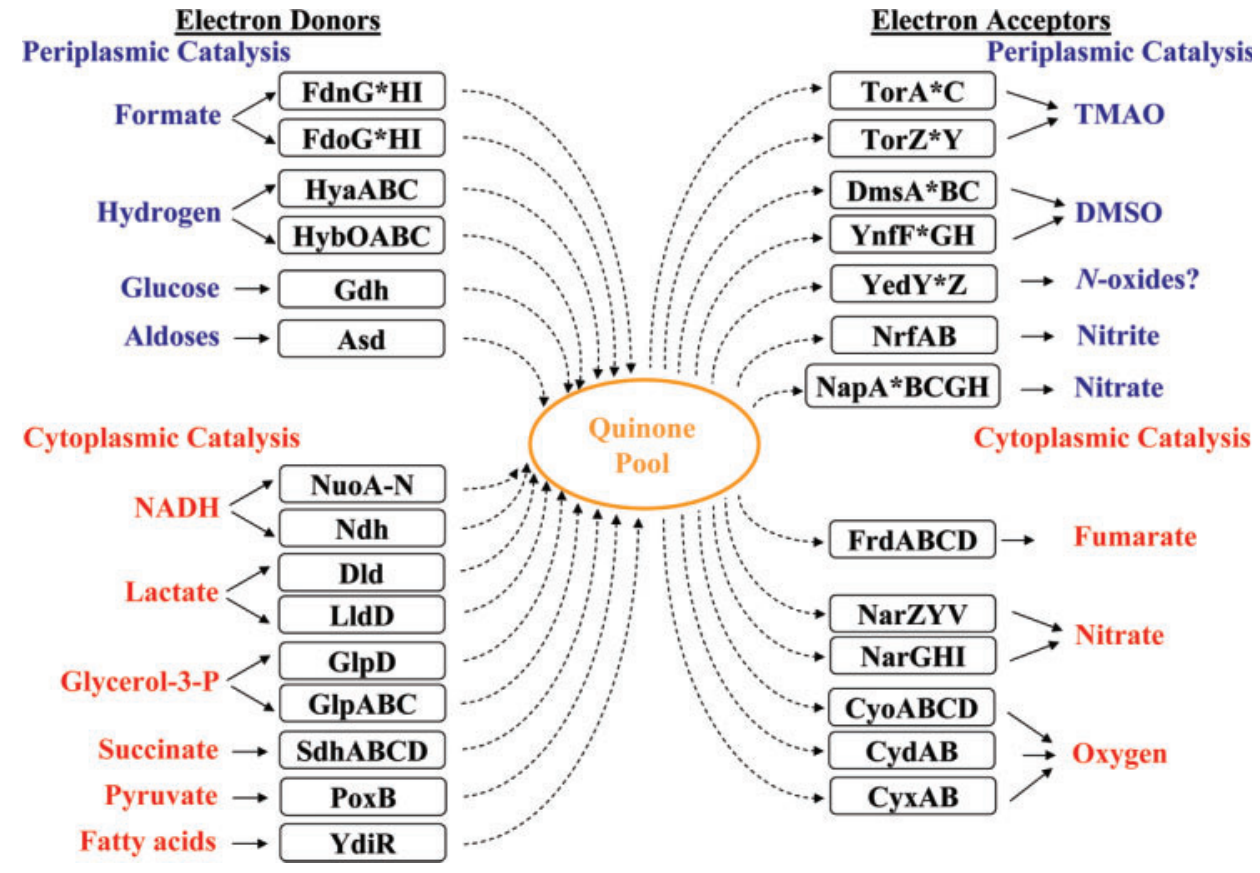

Fig. 1. Respiratory chains of E. coli. A summary of possible electron donors and acceptors that can be used to generate respiratory electron-transport chains in E. coli. Enzymes known, or predicted, to be involved in the metabolism of these compounds are listed by their standard gene-product names. Compounds that are metabolized on the periplasmic side of the inner membrane are coloured red; compounds metabolized on the cytoplasmic side are coloured blue. *Molybdenumcontaining enzymes synthesized with twin-arginine signal peptides.

resolution (Jormakka et al., 2002; Fig. 2A). The 3D crystal structure of the intact nitrate reductase located at the other end of this short respiratory chain has also been solved to near atomic resolution (Bertero et al., 2003; Fig. 2B). The crystal structure of this enzyme, termed nitrate reductase-A (i.e. the predominant nitrate reductase synthesized by $E$. coli) and comprising the NarG, NarH and NarI subunits, confirmed that the quinol-oxidizing site on NarI was located at the periplasmic side, and that the nitrate-reducing site on the NarG subunit was located at the cytoplasmic side, of the membrane (Fig. 2B). The determination of the structural bases for formate-to-nitrate respiration in E. coli has underscored the fundamental importance of enzyme topology in this type of bacterial energy metabolism.

In this review, advances in the understanding of the biosynthetic processes governing assembly and orientation of complex respiratory enzymes will be discussed. In particular, recent genetic, biochemical, biophysical and structural studies of a new family of molecular chaperones (the TorD family) will be used to highlight common principles that underpin biosynthesis of both exported and non-exported respiratory enzymes.

\section{Molybdenum-dependent respiratory enzymes}

The E. coli respiratory formate dehydrogenases and nitrate reductases contain molybdenum as a key catalytic cofactor
(Enoch \& Lester, 1975; Jormakka et al., 2002, 2004; Bertero et al., 2003). The chemical properties of molybdenum, which can cycle between the $\mathrm{Mo}^{\mathrm{IV}}$ and $\mathrm{Mo}^{\mathrm{VI}}$ valence states, have been seized upon by nature and exploited in numerous 2-electron transfer reactions. E. coli formate dehydrogenase$\mathrm{N}$ catalyses the dehydrogenation of formate (Khangulov et al., 1998):

$\mathrm{HCOO}^{-} \rightarrow \mathrm{CO}_{2}+\mathrm{H}^{+}+2 e^{-}$

The active site that catalyses this reaction is located on the FdnG subunit and comprises one molybdenum ion ligated by two molybdopterin guanine dinucleotide (bis-MGD) cofactors and a selenocysteine side-chain (Jormakka et al., 2002). Following dehydrogenation of formate, the electrons are presumably passed via one of the MGD cofactors to an Fe-S cluster located in FdnG and then on to the FdnH subunit, which contains four $\mathrm{Fe}-\mathrm{S}$ clusters, and finally on to FdnI, which has a proximal haem $b$ close to FdnH and a distal haem $b$ close to the quinone-binding site at the cytoplasmic side of the membrane (Jormakka et al., 2002, 2003).

The E. coli respiratory nitrate reductase-A catalyses the 2electron reduction of nitrate to nitrite (an oxotransferase reaction), with the electrons usually being supplied by quinol (Berks et al., 1995; Bertero et al., 2003; Jormakka et al., 2004): 


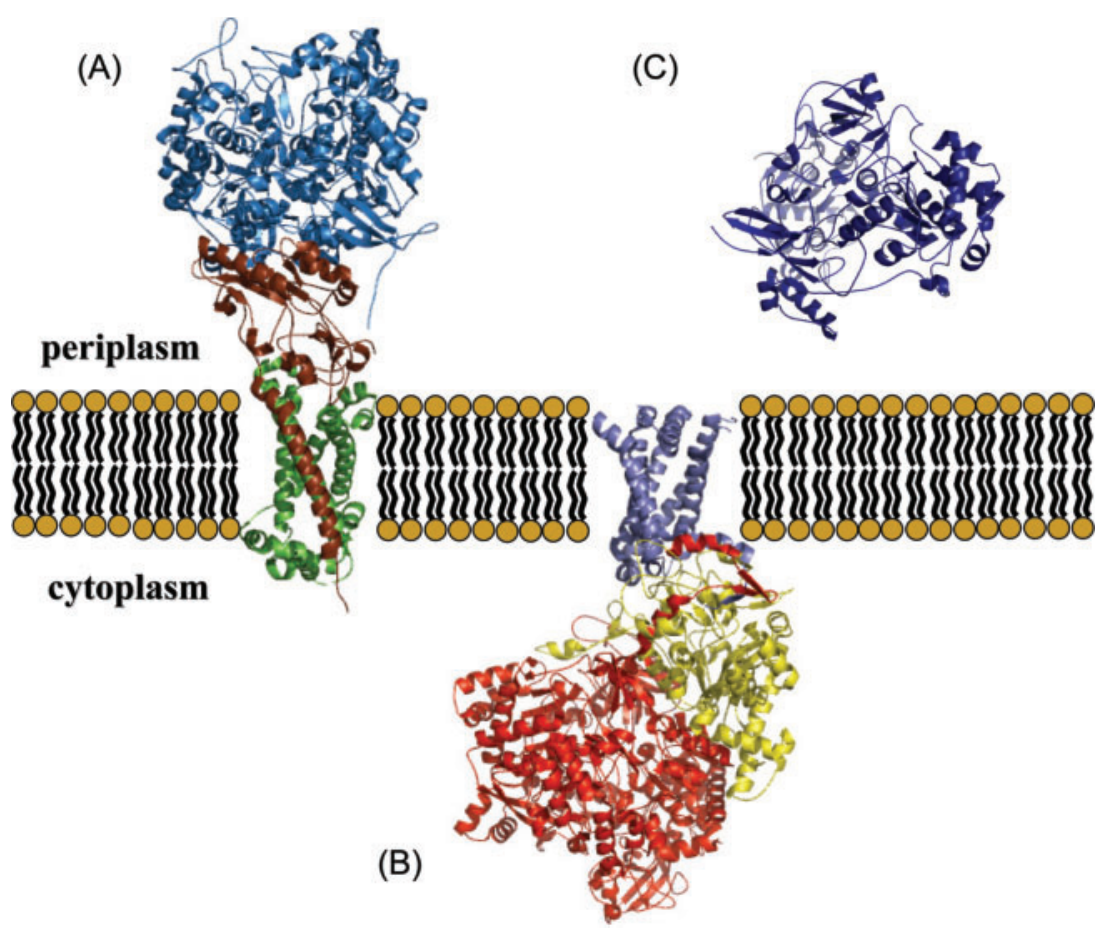

Fig. 2. Structures of FdnGHI, NarGHI and TorA. The crystal structures and subcellular localization of (A) the $E$. coli membranebound formate dehydrogenase-N (PDB accession 1KQF) with FdnG in sky blue, $\mathrm{FdnH}$ in chocolate and $\mathrm{Fdnl}$ in green, (B) the $E$. coli membrane-bound nitrate reductase-A (1016) with $\mathrm{NarG}$ in red, $\mathrm{NarH}$ in yellow and Narl in slate, and (C) the periplasmic TMAO reductase from Shewanella massilia (1TMO). The figure was compiled using PyMol.
$2 e^{-}+2 \mathrm{H}^{+}+\mathrm{NO}_{3}^{-} \rightarrow \mathrm{NO}_{2}^{-}+\mathrm{H}_{2} \mathrm{O}$

The pathway the electrons take through nitrate reductase-A is precisely the opposite to electron transfer in formate dehydrogenase-N. First, quinol binds close to a distal haem $b$ within NarI at the periplasmic side of the membrane, and is reduced to quinone, with the electrons passing from the distal haem to a proximal haem $b$ at the cytoplasmic side of the membrane. The four Fe-S clusters in NarH then channel the electrons to an Fe-S cluster located in the NarG subunit, and finally on to the catalytic molybdenum ion, which is ligated by two MGD cofactors and in this case an aspartate side-chain donated by the NarG polypeptide (Bertero et al., 2003; Jormakka et al., 2004).

When taken together with phylogenetic analyses, the alternative active-site structures of molybdoenzymes such as those of FdnGHI and NarGHI have proven useful in classifying this vast superfamily of enzymes. As a result, the bis-MGDcontaining catalytic proteins themselves can be grouped together into three different types (McDevitt et al., 2002; Jormakka et al., 2004). Type I bis-MGD molybdoenzymes almost always have a cysteine or selenocysteine side-chain as a direct molybdenum ligand (McDevitt et al., 2002; Jormakka et al., 2004), and this group includes E. coli FdnG, E. coli NapA (the periplasmic nitrate reductase), Salmonella TtrA (the catalytic subunit of tetrathionate reductase) (Hensel et al., 1999), and the assimilatory nitrate reductases, for example Synechococcus NarB (Rubio et al., 2002). Type II bis-MGD molydoenzymes display an aspartate molybdenum ligand (Bertero et al., 2003) and include E. coli NarG and its huge array of homologues such as E. coli NarZ, Paracoccus NarG, proteins from bacilli, actinomycetes and the archaea (Richardson et al.,
2001; van Keulen et al., 2005), and Rhodovulum sulfidophilum DdhA, the catalytic subunit of dimethyl sulfide dehydrogenase (McDevitt et al., 2002). Finally, the type III bis-MGD molybdoenzymes possess a serine ligand to the molybdenum and include the E. coli TMAO reductases (TorA and TorZ), E. coli DmsA (the catalytic subunit of dimethyl sulfoxide (DMSO) reductase), the TMAO/DMSO reductases of Rhodobacter sp., and the E. coli biotin sulfoxide reductase, BisC (Pierson \& Campbell, 1990).

The type I, II and III classification of bis-MGD molybdoenzymes, however, does not discriminate between exported and non-exported proteins. For example, under type I there are the periplasmic FdnG and NapA proteins together with the cytoplasmic FdhF and NarB enzymes. Under type II there is the cytoplasmically oriented E. coli NarG together with the periplasmic $R v$. sulfidophilum DdhA. Under type III there is the cytoplasmic E. coli BisC enzyme together with the E. coli periplasmic TorA enzyme as well as, most strikingly, the Shewanella DMSO reductases which reside on the outer leaflet of the outer membrane (Gralnick et al., 2006). Since correct targeting of respiratory enzymes to their sites of physiological function is clearly an essential feature for prokaryotic respiration, the cell is faced with a problem of logistics: how to assemble homologous enzymes in different cellular compartments. The solution, it seems, is to assemble the enzymes in the cell cytoplasm then, if necessary, perform the translocation step last.

\section{The twin-arginine transport system}

Many eubacteria and archaea (and their chloroplast descendants) have the ability to transport pre-folded, very often oligomeric, and enzymically active respiratory 
enzymes across ionically sealed membranes (Palmer \& Berks, 2003; Berks et al., 2003). The proteins so transported are usually synthesized with, or associated with folded partner proteins that possess, distinctive N-terminal signal peptides that bear a common 'twin-arginine' SRRxFLK amino acid sequence motif (Berks, 1996). Twin-arginine signal peptides have a common tripartite structure that includes a polar N-terminal (n-) region of variable length, a moderately hydrophobic (h-) region of 12-20 amino acids, and a C-terminal (c-) region that often contains basic residues (Table 1 ). The consensus motif is always located at the junction between the $n$ - and h-regions (Table 1). These conserved common features have led to the development of algorithms designed to identify twin-arginine signal peptides from genomic information (Rose et al., 2002; Bendtsen et al., 2005). E. coli is predicted to produce $\sim 26$ such proteins and the vast majority of these are cofactorcontaining respiratory enzymes (Berks et al., 2005). Indeed, all of the extracellular molybdoenzyme complexes synthesized by E. coli are either known or predicted to possess a subunit with an $\mathrm{N}$-terminal twin-arginine signal peptide, including the type I molybdoproteins FdnG and NapA, and the type III molybdoenzymes TorA and DmsA (Fig. 1). Some other prokaryotes make more extensive use of the twin-arginine signal peptide; for example the genome of the Gram-positive actinomycete Streptomyces coelicolor is predicted to encode upwards of 250 diverse proteins bearing twin-arginine signal peptides (Dilks et al., 2003; Widdick et al., 2006), and almost all exported proteins expressed by some halophilic archaea are predicted to contain twin-arginine signal peptides (Bolhuis, 2002; Rose et al., 2002).

All proteins bearing bona fide twin-arginine signal peptides are transported by the twin-arginine translocation (Tat) system (Sargent et al., 1998a; Palmer \& Berks, 2003). The Tat translocase is essentially a membrane-bound nanomachine dedicated to the transmembrane translocation of fully folded proteins. Depending on the biological model system under investigation, the complete Tat translocation machinery comprises two or three different proteins. In E. coli, three types of integral membrane proteins - TatA (and its homologue TatE), TatB, TatC - have been identified that are involved in the transport process (Bogsch et al., 1998; Sargent et al., 1998a, 1999; Weiner et al., 1998). TatA/E and TatB are predicted to be structurally related, each comprising a single $\mathrm{N}$-terminal transmembrane $\alpha$-helix with the extreme $\mathrm{N}$-terminus on the periplasmic side of the membrane (Settles et al., 1997; Chanal et al., 1998; Lee et al., 2006). The TatC protein has six transmembrane helices, with both termini at the cytoplasmic side of the membrane (Drew et al., 2002; Behrendt et al., 2004; Ki et al., 2004). Some other bacteria, including the Gram-positive Bacillus subtilis, have minimalist Tat translocation systems that comprise only TatA and TatC (Jongbloed et al., 2006). Indeed, the Gram-positive Staphylococcus aureus has a genome that lacks a tatB homologue altogether (Pop et al., 2002). In E. coli TatB is essential for physiological Tat

Table 1. Classification of twin-arginine signal peptides

\begin{tabular}{|c|c|c|c|c|}
\hline \multicolumn{2}{|c|}{ Tat signal peptide structure } & c-region-c & \multirow[b]{2}{*}{ Cleaved } & \multirow[b]{2}{*}{ Chaperone } \\
\hline Prokaryote & Protein & Peptide Sequence & & \\
\hline \multicolumn{5}{|c|}{ A-Class Signal Peptides (Targeting and Biosynthesis) } \\
\hline E. coli & TorA & 1-MNNNDLFQASRRRFLAQLGGLTVAGMLGPS LITPRRATA-39 & Yes & TorD \\
\hline E. coli & DmsA & 1-MKTKI PDAVLAAEVSRRGLVKT AIGGLAMASSALT LPESRIAHA-45 & Yes & DmsD \\
\hline A. fulgidus & NarG & 1-MKVSRRDFIKLSAAT AFASGLGLGYFQKSRGV-32 & unknown & NarJ?* \\
\hline H. mediterranei & NarG & 1-MDADSGVSRRTFLE GIGVAS LLGIGTSAASDDSLFQ-36 & unknown & NarJ? \\
\hline P. aerophilum & NarG & 1-MLKTTRRRMLA GVAT ISAAAWVMALAQNLQYLQ-33 & unknown & NarJ? \\
\hline Ha. marismortui & NarG & 1-MSRNDLTDDEGDSAGISRRDFVR GLGAAS LLGAT GLSFADDGMD-43 & unknown & NarJ? \\
\hline \multicolumn{5}{|c|}{ B-Class Signal Peptides (Targeting Only) } \\
\hline E. coli & AmiC & 1-MSGSNTAISRRRLLQGAGAMWLLS VSQVSLA-31 & Yes & none to date \\
\hline S. coelicolor & DagA & 1-MVNRRDLIKWSAVALGAGAGLAGPAPAAHA-30 & Yes & none to date \\
\hline \multicolumn{5}{|c|}{ C-Class Remnant Signals (Biosynthesis Only) } \\
\hline E. coli & NarG & 1-MSKFLDRFRYFKQKGE TFADGHGQLLNTNRDWEDGY-36 & No & NarJ \\
\hline B. subtilis & NarG & 1-MKKKKRSPLERRLNYFS PIEHHSNKHSQTTREDRDWENVY-40 & No & NarJ? \\
\hline P. pantotrophus & NarG & 1-MSHLLDRLNFLKSTRKDVFSEGHGQTTTENRDWEDTY-37 & No & NarJ? \\
\hline E. coli & BisC & 1-MANSSSRYSVLTAAHWGPMLVETDGETVFSSRGALA-36 & No & none to date \\
\hline \multicolumn{5}{|l|}{ N-tail } \\
\hline T. thermophilus & NarG & 1-MRDWIKEVENPAERKWEEFY-20 & No & none to date \\
\hline
\end{tabular}


transport activity and seems to form a link between TatA and TatC in the inner membrane (Sargent et al., 1999; Bolhuis et al., 2001).

Two distinct Tat complexes can be isolated from resting $E$. coli inner membranes. TatA can be purified as a large, heterogeneous complex of up to $600 \mathrm{kDa}$ (McDevitt et al., 2005) that also contains trace amounts of TatB (Sargent et al., 2001; de Leeuw et al., 2002; Porcelli et al., 2002; Oates et al., 2005). The TatC protein is found in another large complex with an equimolar amount of TatB (Bolhuis et al., 2001; de Leeuw et al., 2002; Oates et al., 2003; McDevitt et al., 2005; Richter \& Brüser, 2005). TatBC is the 'signal recognition module' of the Tat system and contains the recognition site for the twin-arginine motif on the signal peptide (Mori \& Cline, 2002; Alami et al., 2003). Lowresolution structural analysis points to the TatA protein forming the 'transport module' of the Tat system - i.e. numerous bundles of TatA may form the protein-conducting channel (Gohlke et al., 2005; Dabney-Smith et al., 2006). During protein transport a transient TatABC complex is thought to form in the membrane, but then rapidly dissociate again once the transport step has been completed (Mori \& Cline, 2002). The whole system is probably powered by the transmembrane proton-motive force (Alder \& Theg, 2003), although this is controversial (Finazzi et al., 2003; Theg et al., 2005).

The establishment of the Tat pathway as an exciting, vibrant and fast-moving research area was preceded by a long gestation period. During that time microbiologists studying complex respiratory enzymes recognized the importance of the signal peptide and its twin-arginine motif (e.g. van Dongen et al., 1988; Nivière et al., 1992; Bernhard et al., 1996; Dreusch et al., 1997) and, with a hint of irony, some had already isolated tat mutant strains and even sequenced the genes (e.g. Friedrich et al., 1981; Yates et al., 1997). In parallel, plant scientists were characterizing biochemically a thylakoid protein transport system for folded proteins in which twin-arginine signal peptides were critical to the targeting process (e.g. Creighton et al., 1995; Chaddock et al., 1995). Mutant plants defective in this transport system had also already been isolated (Voelker \& Barkan, 1995). Any possible commonality between the work of the microbial and plant research groups was originally dismissed because the substrate proteins transported by the plant thylakoid system were not present in cyanobacteria or any other prokaryotes. The seminal hypothesis of Berks (1996), however, raised the possibility that a prokaryotic protein transport system for folded proteins was indeed waiting to be unearthed. The race to identify components of the translocase was won by the plant scientists, who cloned and sequenced a gene subsequently shown to encode a homologue of E. coli TatB (Settles et al., 1997; Weiner et al., 1998; Sargent et al., 1998a; Chanal et al., 1998).

The central dogma of the Tat research field is that this system has evolved for the transmembrane translocation of fully folded proteins. That is not to say the Tat translocase cannot transport unfolded or misfolded proteins, as this has been clearly shown for the thylakoid Tat system (e.g. Hynds et al., 1998). Nevertheless, in the case of eubacteria such as $E$. coli where the majority of Tat substrates are cofactorcontaining, multi-subunit, respiratory enzymes, and in halophilic archaea, where protein folding in the extracellular environment would be biophysically impossible, the ultimate challenge in the Tat research field is to understand the molecular mechanism of the transport of fully folded proteins.

\section{Biosynthesis of TorA, a paradigm Tat-targeted respiratory enzyme}

The ultimate aim for a bacterial physiologist would be to understand how a multi-subunit, multi-cofactor enzyme like formate dehydrogenase- $\mathrm{N}$ is assembled and transported across a membrane. In the first step, the $\mathrm{Fe}-\mathrm{S}$ cluster and molybdenum cofactor must be loaded into FdnG (which also contains the twin-arginine signal peptide). At the same time the four $\mathrm{Fe}-\mathrm{S}$ clusters must be loaded into $\mathrm{FdnH}$. The FdnGH complex must then be formed in the cytoplasm before transport of the dimer via the Tat system to the periplasm. Next, part of FdnH must be integrated into the membrane (Hatzixanthis et al., 2003) before FdnGH associates with FdnI (which will have already followed a different biosynthetic pathway) and finally forms a 'trimerof-trimers' in the membrane. All this must occur before a single molecule of formate is oxidized. The complexity of this 'protein production line' raises many questions about 'quality control' and coordination of different biological events. Why, for example, is the FdnG protein not exported without its FdnH partner? Because of the myriad of different processes that need to be considered when studying the biosynthesis of a large enzyme like formate dehydrogenase$\mathrm{N}$, most of the early research in this area focused on a simpler, more tractable system.

The E. coli TMAO reductase (TorA) enzyme is a type III molybdoenzyme (McDevitt et al., 2002) and is a watersoluble periplasmic protein that contains bis-MGD as its only cofactor. Crystal structures of TorA homologues from Shewanella massilia (Czjzek et al., 1998), Rhodobacter capsulatus (Schneider et al., 1996; McAlpine et al., 1998) and Rhodobacter sphaeroides (Schindelin et al., 1996) are available. The E. coli enzyme is abundant under anaerobic conditions in the presence of TMAO, an osmoprotectant found widely in marine animals (McCrindle et al., 2005), and the evidence for cytoplasmic assembly and folding of TorA prior to export is strong (reviewed by Berks et al., 2003).

The biosynthesis of the MGD cofactor itself has been extensively studied and crystal structures are now available for most of the biosynthetic enzymes. This entire process requires the elaborate use of nucleotide cofactors and so occurs exclusively in the cytoplasm (reviewed by Schwarz, 2005). To summarize, the biosynthesis of the cofactor is mediated by 10 proteins each given the prefix 'Mo-'. 
First, the MoaAC complex rearranges GTP into a pterin called cyclic pyranopterin monophosphate (cPMP) in a process requiring $S$-adenosylmethionine. Thiol groups are next added to cPMP in an elaborate process driven by protein adenylation and involving MoaD, MoaE and MoeB. The MogA and MoaB proteins then catalyse the ligation of molybdenum to the thiol groups to generate molybdopterin (MPT) and this process involves an adenylation/de-adenylation cycle of the cofactor itself. Finally, a GMP moiety is added to MPT by the MobA protein to generate MGD in a process that may be enhanced by MobB, a cytoplasmic GTPase. The take-home messages from this are that this elaborate cofactor must be constructed in the regulated environment of the cytoplasm, and that its extreme susceptibility to oxidation means that it is very unlikely to be secreted unprotected to the cell exterior.

The next pressing issue is the insertion of the completed MGD cofactor into the TorA apoenzyme. This event occurs before transport of TorA to the periplasm because if the above cofactor biosynthesis pathway is genetically blocked the E. coli TorA apoprotein remains in the cytoplasm (Santini et al., 1998). The experiments of Santini et al. (1998) are compelling and helped to pave the way for the characterization of the bacterial Tat system (Sargent et al., 1998a; Weiner et al., 1998); however, it should be noted that the Rhodobacter TorA homologue behaves quite differently (Buchanan et al., 2001 and references therein). In this case the enzyme is still transported to the periplasm in the absence of cofactor. The most likely explanation is that this particular enzyme folds around GMP instead, as also seen in the crystal structure of NarG purified from a $\mathrm{mo}^{-}$mutant (Rothery et al., 2004), and thus is recognized as a suitable substrate by the Tat translocase. Why does the E. coli TorA enzyme not behave in the same way? Is it possible that E. coli employs a more stringent 'quality control' system which prevents premature export of the apoprotein? The key players in coordinating assembly and export of TorA-type enzymes are the members of a new class of molecular chaperones - the TorD family. Cofactor-loading into E. coli TorA is enhanced both in vivo and in vitro by an accessory protein called TorD (Pommier et al., 1998; Ilbert et al., 2003). The TorD protein binds specifically to the TorA apoenzyme and maintains it in a conformation suitable for cofactor binding (Pommier et al., 1998; Ilbert et al., 2003, 2004; Genest et al., 2005, 2006a, b). However, it is abundantly clear that E. coli TorD is not absolutely essential for cofactor loading into the TorA enzyme since deletion of the tor $D$ gene reduces cellular TorA activity by only around $50 \%$ (Pommier et al., 1998; Jack et al., 2004). By the same token, it should be noted that all the cellular TorA activity in a torD mutant strain is located in the periplasm and the mutant can therefore respire TMAO (Jack et al., 2004; Ilbert et al., 2004). As a result it is also clear that TorD is not absolutely essential for transport on the Tat pathway either. So how and why does the TorD protein recognize and interact with TorA?

\section{The TorD family: structural analyses}

E. coli TorD is encoded by the final gene on the torCAD operon (Mejean et al., 1994) and is a member of a vast family of related bacterial and archaeal proteins (Turner et al., 2004; Ilbert et al., 2004). The sequence databases currently contain hundreds of members of the TorD family which, after sequence analysis, broadly separate into three 'clades': the TorD clade, the DmsD clade and the NarJ clade (Turner et al., 2004). The E. coli genome encodes a total of five members of the wider TorD family - TorD itself, DmsD and YcdY from the DmsD clade, and NarJ and NarW from the NarJ clade (Turner et al., 2004). When overproduced and purified, TorD family proteins can adopt several oligomeric and/or conformational states (Tranier et al., 2002; Sarfo et al., 2004). While the monomeric form always dominates, homodimers and homotrimers have been clearly identified and the 3D crystal structure of a dimer form of the TorD homologue from Shewanella massilia has been solved by X-ray methods (Tranier et al., 2003). The structure of the Shewanella TorD dimer is interesting in several respects, not least because it contains no extensive regions of $\beta$-sheet and, apart from some unstructured loops, is therefore made up entirely of $10 \alpha$-helices (Fig. 3A).

In addition, the Shewanella TorD dimer exhibits domainswapping to the extreme (Fig. 3A; Tranier et al., 2003). Each Shewanella TorD protomer consists of two distinct domains linked by a 'hinge' region. The N-terminal domain, comprising the first six $\alpha$-helices, from one protomer interacts with the $\mathrm{C}$-terminal domain, comprising the last four $\alpha$-helices, of the second protomer, and Tranier et al. (2003) postulated that, based on small-angle solution X-ray scattering, the monomer form of TorD would involve moreor-less identical intra-protomer interactions. The 3D crystal structure of the Salmonella typhimurium LT2 DmsD monomer (Fig. 3B) corroborates this hypothesis completely [Y. Qiu, R. Zhang, V. Tereshko, Y. Kim, F. Collart, A. Joachimiak \& A. Kossiakoff, unpublished; deposited in Protein DataBank in 2004 under 1S9U]. Although sharing only $\sim 15 \%$ overall sequence identity with Shewanella TorD, Salmonella DmsD also displays an all- $\alpha$-helical secondary structure (Fig. 3B) and has an analogous fold to a single 'lobe' of the domain-swapped Shewanella TorD dimer (Fig. 3A).

A third crystal structure of a member of the TorD family is also available (Fig. 3C). The crystal structure of the Af0173 monomer from the hyperthermophilic archaeon Archaeoglobus fulgidus has been solved in a structural genomics project [O. Kirillova, M. Chruszcz, T. Skarina, E. Gorodichtchenskaia, M. Cymborowski, I. Shumilin, A. Savchenko, A. Edwards \& W. Minor, Midwest Center For Structural Genomics, unpublished; deposited in Protein DataBank in 2005 under 1ZE0]. The Af0173 protein is a peripheral member of the NarJ clade (Turner et al., 2004). Despite some sequence similarity with $\mathrm{DmsD}$ proteins (Turner et al., 2004), A. fulgidus Af0173 is probably best classified as a NarJ since it is encoded by a four-cistron 


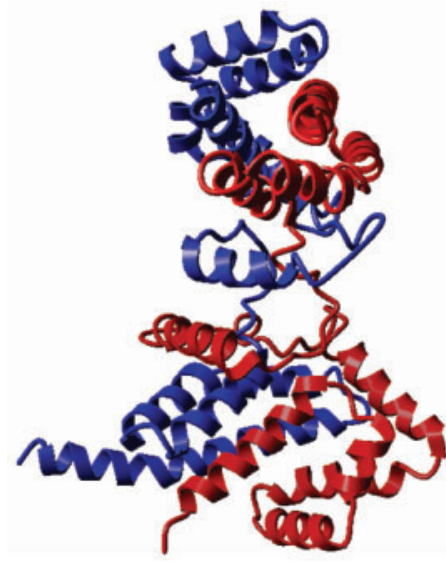

(A) TorD

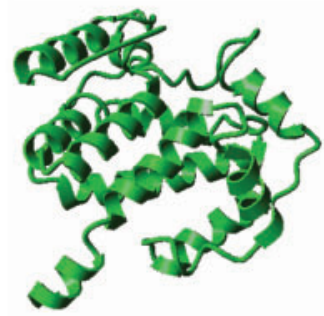

(B) $\mathrm{DmsD}$

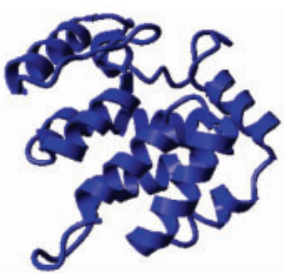

(C) NarJ
Fig. 3. Structures of TorD, DmsD and NarJ. The crystal structures of $(A)$ the TorD homodimer from Shewanella massilia (PDB accession 1N1C), (B) the DmsD monomer from Salmonella typhimurium (1S9U) and (C) the NarJ monomer from Archaeoglobus fulgidus (1ZE0) are shown. The figure was compiled using Yasara. cluster also containing the genes for a NarG-type nitrate reductase Af0176 (Richardson et al., 2001; Dridge et al., 2006), an Fe-S protein with limited homology with $\mathrm{NarH}$ (Af0175), and an unusual integral membrane protein, Af0174 (Dridge et al., 2006). Thus it is clear from the 3D structures available that a common fold is conserved across this entire family of proteins (Fig. 3).

\section{The TorD family: twin-arginine signal peptide- binding proteins}

The identification of E. coli DmsD as a cytoplasmic twinarginine signal peptide-binding protein was a watershed in the understanding of how TorD family proteins work. The E. coli DMSO reductase is a trimeric complex comprising the DmsA catalytic subunit, which contains bis-MGD and an $\mathrm{Fe}-\mathrm{S}$ cluster as cofactors, the DmsB protein, which contains four $\mathrm{Fe}-\mathrm{S}$ clusters, and an unusual integral membrane protein termed DmsC (Bilous et al., 1988). The DmsA protein contains a twin-arginine signal peptide at its N-terminus (Berks, 1996; Sambasivarao et al., 2000) and this single signal peptide directs the export of the DmsAB dimer to the periplasmic side of the membrane, where it finally attaches to the DmsC membrane protein to form the holoenzyme (Stanley et al., 2002). Oresnik et al. (2001) developed an affinity chromatography method to detect proteins that bound tightly to the E. coli DmsA twinarginine signal peptide, and the primary interactor was identified as YnfI (re-named DmsD). The DmsD protein is encoded by the $y n f E F G H d m s D$ operon for a second (essentially cryptic) DMSO reductase in E. coli (Lubitz \& Weiner, 2003). A study of the Tat transport activity of the DmsA signal peptide in the absence of $d m s D$ suggested that DmsD does not have an obligate role in transport per se (Ray et al., 2003), and therefore does not operate as a kind of 'signal recognition particle'. However, DmsD was certainly found to be essential for cellular DMSO respiration and DMSO reductase activity, which demonstrated that the signal-peptide-binding event was, in this case, critical for the biosynthesis of the native substrate (Ray et al., 2003).
The sequence similarity between DmsD and TorD suggested strongly that TorD could also be a twin-arginine signal peptide-binding protein (Sargent et al., 2002). This was initially confirmed genetically using a bacterial two-hybrid screen with tor $D$ as 'bait' against a random genomic library as 'prey' (Jack et al., 2004). The strongest interacting clones identified by this completely blind screen encoded the Tat signal peptide of TorA (Jack et al., 2004). The powerful biophysical technique of calorimetry was subsequently used to characterize in vitro the interaction between TorD and a synthetic TorA signal peptide. The isolated E. coli TorD monomer binds to the TorA signal peptide with an apparent dissociation constant $\left(K_{\mathrm{d}}\right)$ of $\sim 1 \mu \mathrm{M}$ (Hatzixanthis et al., 2005). By comparison, recent calorimetric experiments have shown E. coli DmsD to bind the DMSO reductase Tat signal peptide with an apparent $K_{\mathrm{d}}$ of $0.2 \mu \mathrm{M}$ (Winstone et al., 2006). Optimum ligand binding to TorD requires a $27-$ residue fragment of the TorA signal peptide stretching from the twin-arginine motif, through the h-region, to another arginine dipeptide at the C-terminus (Hatzixanthis et al., 2005). The nature of the peptide-binding site has not yet been visualized for any TorD family member, and it is not immediately obvious from the available crystal structures where the peptide-binding site might be located. It is likely, however, that the TorA signal peptide is unstructured in aqueous solution, as this has been shown to be the case for the twin-arginine signal peptides of the Allochromatium vinosum high-potential iron protein (HiPIP) (Kipping et al., 2003) and the E. coli SufI protein (San Miguel et al., 2003). Note, however, that such an unstructured peptide would be excessively lengthy when compared to the folded, globular, TorD monomer. To be bound in its entirety by TorD, the TorA signal peptide will certainly need to adopt a high degree of secondary structure. Given the all-helical nature of TorD family proteins (Fig. 3), it is possible the signal peptide could also display an $\alpha$-helical conformation in the TorD-bound state, such as occurs when the signal peptide of the Sec substrate LamB is bound by the SecA protein (Chou \& Gierasch, 2005). 
What is TorD actually doing when it binds to the TorA signal peptide? One possibility is that the binding event simply protects the exposed, unstructured, signal peptide from degradation by cytoplasmic proteases prior to export ( $\mathrm{Li}$ et al., 2006; Genest et al., 2006a). For example, when the native TorA enzyme was overproduced in the absence of TorD the signal peptide was prematurely cleaved within the c-region betwixt the arginine dipeptide at positions 35 and 36 (Table 1). However, co-expression of TorA with TorD prevented this degradation, presumably because chaperonebinding sterically hindered attack by a protease (Genest et al., 2006a). It is certainly true that premature degradation of the TorA precursor would undoubtedly be deleterious to the assembly process. The physiological relevance of this particular observation, however, remains in question since the protease cleavage site on TorA appears to fit exactly with the OmpT recognition sequence $(\mathrm{R} / \mathrm{K}) \downarrow(\mathrm{R} / \mathrm{K})$-A (Dekker et al., 2001), and OmpT is an outer-membrane protease that would not normally be exposed to cytoplasmic substrates (Vandeputte-Rutten et al., 2001). Moreover, experiments with the TorA signal peptide fused to a $[\mathrm{NiFe}]$ hydrogenase suggest a more sophisticated modus operandi for TorD (Jack et al., 2004).

E. coli hydrogenase- 2 is a heterodimer of a nickel-containing $\alpha$-subunit ( $\mathrm{HybC}$ ) and an $\mathrm{Fe}-\mathrm{S}$ cluster-binding $\beta$-subunit (HybO) (Sargent et al., 1998b). Only the HybO protein bears a twin-arginine signal peptide and the $\alpha \beta$ dimer is transported as a pre-formed active complex by the Tat translocase (Rodrigue et al., 1999; Sargent et al., 1998a). This observation raised many questions, one of the most compelling being: what prevents premature export of $\mathrm{HybO}$ without its HybC partner? One possible answer came some years later when Jack et al. (2004) swapped the native signal peptide of E. coli HybO for that of TorA. The assembly of the TorA::hydrogenase-2 chimera was disrupted such that the HybO subunit carrying the TorA signal peptide was targeted prematurely to the membrane without its $\mathrm{HybC}$ partner and as a result cellular hydrogenase activity dropped dramatically in this strain (Jack et al., 2004). Most remarkably, perhaps, this mutant phenotype could be rescued by overproduction of TorD - cellular hydrogenase activity returned since the HybOC dimer was once again correctly assembled and exported (Jack et al., 2004). In this case, protection of the TorA signal peptide from proteolysis was probably not an issue because the TorA : : HybO fusion was not being degraded and was still being targeted in a Tatdependent manner (Jack et al., 2004). Instead, TorD was somehow coordinating assembly and export of the hydrogenase. This result had wide-ranging connotations. First, it meant that what was previously assumed to be a private chaperone for a molybdenum enzyme (e.g. Pommier et al., 1998), could actually be employed in the maturation of a completely 'alien' enzyme with no molybdenum cofactors at all. Second, it meant that a significant part of TorD's biological activity was focused solely on the TorA signal peptide with scant regard to the passenger protein to which the signal peptide was attached. Indeed, this finding was corroborated when Li et al. (2006) showed that extra copies of torD could enhance the levels of periplasmic jellyfish green fluorescent protein (GFP) when it was routed through the Tat pathway by the TorA signal peptide. Third, the action of TorD on the TorA signal peptide must mimic almost exactly a biochemical process normally central to the native hydrogenase assembly pathway (probably the precursor-binding activity of the HybE protein: Dubini \& Sargent, 2003; Jack et al., 2004; Butland et al., 2006). These papers, and others, led to the hypothesis that TorD was acting as a 'Tat proofreading chaperone', which is actually preventing protein export by shielding the signal peptide from the Tat translocase until all assembly processes are complete (Santini et al., 1998; Wu et al., 2000; Sargent et al., 2002; Dubini \& Sargent, 2003; Jack et al., 2004, 2005).

The phrase 'proofreading' in this context of enzyme assembly is akin to a 'quality control' process (i.e. checking that folding is complete, as opposed to scanning for specific 'mistakes'). However appropriate here, it should be noted well that the term 'quality control' in the Tat transport field had already been coined by Delisa et al. (2003) for a mechanism by which the TatABC translocase itself accepts or rejects proteins for export based on their folded state. As a result the term 'Tat proofreading' is preferred to distinguish the pre-export chaperone-mediated system described here (Jack et al., 2005).

Under laboratory conditions the stringency of different Tat proofreading systems is variable. The phenotype of an E. coli $d m s D$ mutant is severe and results in complete disruption of DMSO reductase biosynthesis and blockage of all anaerobic respiration with DMSO as electron acceptor (Oresnik et al., 2001; Ray et al., 2003). This is different to that observed for an E. coli torD deletion mutant, in which respiration with TMAO is not significantly hampered and TorA levels are only reduced by around 50\% (Pommier et al., 1998; Jack et al., 2004). The differences are probably not due to the different structures of the TMAO and DMSO reductases in $E$. coli since disruption of the single dorD gene from Rhodobacter capsulatus, which encodes a TorD homologue, was enough to completely abolish activity of the cognate TorA-type reductase (Shaw et al., 1999). These discrepancies are not easy to explain, although it should be considered that another member of the TorD family may be participating in TorA maturation in E. coli in the absence of TorD.

\section{The involvement of nucleotides in TorD function}

Clearly, TorD binds tightly and specifically to the TorA signal peptide in an energetically favourable reaction, i.e. with a large negative Gibbs free energy change (Hatzixanthis et al., 2005). In the cell a physiological 'TorD cycle' could be envisaged in which the Tat proofreading chaperone would first bind, but then release, the TorA signal peptide once cofactor loading and protein folding were complete. What, if anything, triggers signal peptide release by TorD? It is certainly possible that, akin to the mitochondrial protein import system (Stan et al., 2000), the TorA signal peptide 
would be naturally 'handed over' from TorD to the TatBC signal-binding module if TatBC has a significantly lower $K_{\mathrm{d}}$ (and thus a more negative Gibbs free energy for binding) for the signal peptide than TorD. To date, rigorous experiments to determine the binding affinity of twin-arginine signal peptides to TatBC have not been reported. Moreover, this particular model lacks any obvious control mechanism. An alternative hypothesis was put forward by Hatzixanthis et al. (2005) and was based on the known molecular mechanisms of other peptide-binding proteins: given the nucleotidebased mechanisms of the signal recognition particle (Doudna \& Batey, 2004; Focia et al., 2004), the SecA protein (Vrontou \& Economou, 2004) and the DnaKDnaJ-GrpE system (Ellis \& Hartl, 1999), TorD was also tested for its ability to interact with nucleotide triphosphates (Hatzixanthis et al., 2005).

By monitoring intrinsic tryptophan fluorescence, isolated TorD was shown to interact loosely $\left(K_{\mathrm{d}} \sim 375 \mu \mathrm{M}\right)$ with GTP in vitro (Hatzixanthis et al., 2005). No GTP hydrolysis was observed, but the affinity for GTP was increased (to an apparent $K_{\mathrm{d}} \sim 200 \mu \mathrm{M}$ ) by pre-incubation of TorD with the TorA signal peptide (Hatzixanthis et al., 2005). This finding was controversial because TorD is an all-helical protein (Fig. 3) and as such does not display a classic nucleotidebinding Rossmann fold (Rossmann et al., 1975) or canonical 'Walker-A' (or 'P-loop') or '-B' nucleotide-binding amino acid motifs (Walker et al., 1982). Nevertheless, inspection of the primary sequences of TorD family proteins does suggest some similarity with metal-dependent phosphohydrolases. The interdomain 'hinge' region of TorD family proteins contains a very highly conserved $\mathrm{EPXH}$ amino acid motif where the aspartate is invariable and the histidine is only very occasionally substituted by tyrosine (Tranier et al., 2003; Ilbert et al., 2004; Turner et al., 2004). Indeed, in E. coli TorD the D-124 and $\mathrm{H}-125$ residues within this signature have been shown to be essential in the in vivo Tat proofreading process (Jack et al., 2004). This motif is highly reminiscent of those identified in a range of phosphohydrolases including the GNH[DE] superfamily (Aravind \& Koonin, 1998b), the HKD phospholipases (Koonin, 1996) and the DHH phosphoesterases (Aravind \& Koonin, 1998a). Most notable of all, perhaps, is the HD superfamily of phosphohydrolases, which includes dGTPases, ppGpp hydrolases and cyclic-di-GMP phosphodiesterases (Aravind \& Koonin, 1998c; Galperin et al., 2001; Yakunin et al., 2004; Ryan et al., 2006). The aspartate and histidine side-chains in these systems are usually the ligands for magnesium or manganese cofactors (e.g. Yamagata et al., 2002), ions that are also intimately linked with classical nucleotide-hydrolysing systems (e.g. Walker et al., 1982). It is notable, of course, that the available crystal structures (Fig. 3) do not show any opportunistic metal binding at the EPxDH motifs, and it has also been shown that GTP binding by E. coli TorD is magnesium-independent (Hatzixanthis et al., 2005). Therefore, if the EPxDH motif is not a metalbinding site it is also worth considering that members of the J-domain co-chaperone family (including E. coli DnaJ) contain a functionally important conserved DPH tripeptide in their sequences (e.g. Mayer et al., 1999). As with the TorD EPxDH motif, the DnaJ DPH signature is located in a loop between two $\alpha$-helices, and, most importantly, has been shown to be involved in mediating protein-protein interactions with DnaK (e.g. Mayer et al., 1999).

It is worth considering at this point the alternative possibility that the observed GTP binding by E. coli TorD (Hatzixanthis et al., 2005) is more closely related to the role of TorD in assisting molybdenum cofactor insertion into TorA (Pommier et al., 1998) rather than Tat proofreading (Jack et al., 2004). Since the molybdenum cofactor in question (MGD) is a pyranopterin dinucleotide where the pyranopterin moiety is itself derived from rearranged GTP and is linked via a phosphate bridge to another guanosine (Schwarz, 2005), is it possible Hatzixanthis et al. (2005) have identified an MGD-binding site on TorD rather than a GTPbinding pocket? The available evidence argues against this. First, the $K_{\mathrm{d}}$ for GTP binding would seem to be too high to account for efficient binding of MGD, of which there is apparently very little in the cell (Johnson et al., 1991). Second, the Tat proofreading activity of TorD has been shown to be biochemically distinct from the cofactor insertion activity (Jack et al., 2004). In contrast, Hatzixanthis et al. (2005) have shown that GTP binding by TorD is intimately linked to signal peptide binding since its presence served to increase the affinity of TorD for GTP about twofold. Third, molybdoenzymes purified in the absence of MGD cofactor often bind GMP or GDP in their active sites by default (e.g. Rothery et al., 2004; Temple \& Rajagopalan, 2000). Opportunistic insertion of the more abundant GTP into vacant MGD-binding sites has never been reported. Finally, further molecular modelling suggests that the pyranopterin moiety of MGD does not fit into the hypothetical GTP-binding pocket described by Hatzixanthis et al. (2005). Molecular modelling can, of course, superimpose the guanosine moiety of MGD onto GTP in the putative binding site; however, numerous apparent steric clashes prevent binding of the pyranopterin half of the molecule (A. Oubrie \& F. Sargent, unpublished).

The latest working model for the TorD cycle (as proposed by Hatzixanthis et al., 2005) takes into account the direct signal peptide-binding activity of this protein and its homologues, as well as the putative binding of GTP (Fig. 4). Since affinity for GTP is increased by pre-incubation of TorD with the TorA signal peptide (and pre-loading of TorD with GTP did not enhance signal peptide binding), it is proposed that TorD binds the TorA signal first, then GTP binds, then either GTP hydrolysis or nucleotide exchange drives a conformational change in TorD that results in signal peptide release (Fig. 4). The missing link in this model, however, is the trigger for signal release - how does TorD know when to release the signal peptide; how does it know TorA maturation is complete? It seems unlikely that TorD can specifically sense the TorA protein itself, otherwise the experiments with hydrogenase (Jack et al., 2004) and GFP 


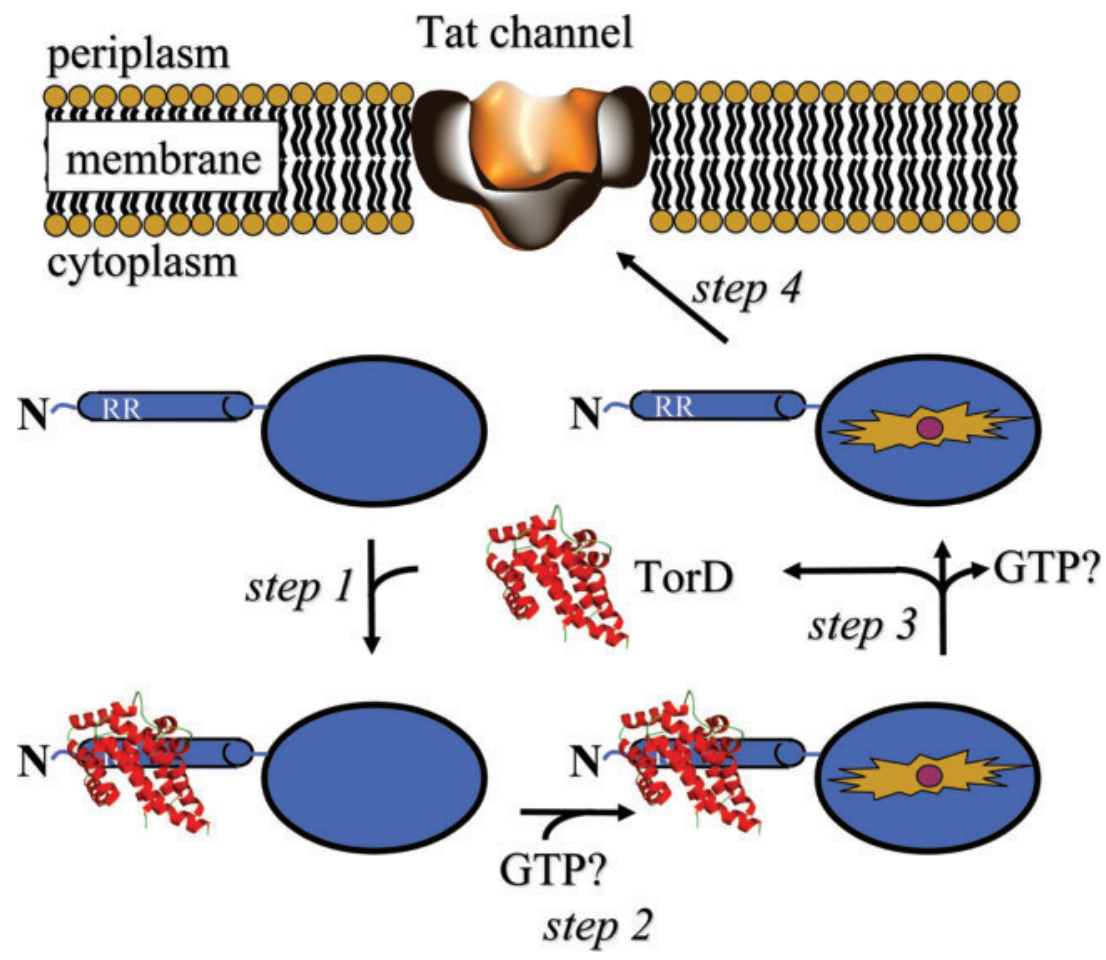

Fig. 4. The Tat proofreading mechanism - the TorD cycle. A model for chaperonemediated Tat proofreading. An apoprotein bearing a twin-arginine signal peptide is first released from the ribosome. Step 1: a proofreading chaperone (TorD) binds to the twinarginine signal peptide, thus preventing premature export. Step 2: GTP binding to TorD may follow and cofactor-loading into the mature portion of the protein is completed. Step 3: TorD is released, possibly in a GTP-dependent manner. Step 4: targeting of the precursor to the Tat translocon can commence.

(Li et al., 2006) fusions to the TorA signal peptide would likely not work. It is possible, if TorD binds close enough to the junction between signal peptide and mature domain as some studies suggest (Genest et al., 2006a), that folding of the passenger protein could sequester part of the binding site and thus force off the chaperone, although it should be noted that the free energy released in most protein-folding events is relatively small. There is some evidence to suggest that the TorD family protein $\mathrm{DmsD}$ interacts with the Tat machinery at the cytoplasmic membrane (Papish et al., 2003). It is therefore conceivable that the action of a component of the Tat system could induce signal peptide release and/or GTP hydroloysis. One attractive alternative hypothesis, however, is that TorD operates as a 'molecular clock' (Berks et al., 2005), perhaps along similar lines as described for proteins involved in flagellar biosynthesis in Salmonella (Moriya et al., 2006). In this model the signal peptide release rate (effectively the dissocation rate constant, $K_{\text {off }}$ ) would coincide with the rate of assembly of the passenger protein.

\section{Dual functionality of twin-arginine signal peptides}

It is now clear from signal-swapping experiments (Sambasivarao et al., 2000; Jack et al., 2004), and from the recent studies of the chaperone-mediated Tat proofreading system decribed above, that some twin-arginine signal peptides have a separate biological role distinct from that of protein targeting: biosynthesis. As a result, twin-arginine signal peptides have been separated into two broad classes, 'class 1' containing those signal peptides with dual functions in biosynthesis (i.e. chaperone binding) and targeting, and 'class 2' containing those with a role in targeting only
(Sargent et al., 2006). The terminology chosen to classify these signal peptides, however, was not altogether satisfactory and could conceivably cause some confusion with the different classes of Sec signal peptide (e.g. Tokuda \& Matsuyama, 2004). It is therefore proposed here to dub instead the dual-function Tat signal peptides as 'A-class' and the targeting-only Tat signal peptides as 'B-class' (Table 1).

\section{Common principles in the assembly of molybdoenzymes...}

If dual-function A-class Tat signal peptides (transport and biosynthesis) can be identified, and mono-function B-class Tat signal peptides (transport only) have been identified, is it possible to close the loop and identify mono-function ' $\mathrm{C}$ class' peptides that would have a biosynthetic function but have no role in protein transport? The answer is probably 'yes'.

The N-terminal regions of non-exported eubacterial (type II) NarG proteins show a striking resemblance to twinarginine signal peptides (Table 1) (Turner et al., 2004). The crystal structure of the non-exported NarG protein from $E$. coli shows a long N-terminal ('N-tail') domain (Bertero et al., 2003) that has amino acid signatures that follow so closely the canonical SRRxFLK Tat motif that it has been termed a 'vestigial' (or perhaps 'remnant' is a better description), twin-arginine signal peptide (Turner et al., 2004). Similar remnant signal peptides can be identified on the NarG homologues from Paracoccus pantotrophus and Bacillus subtilis (Table 1). Indeed, a remnant signal is also present on the type III molybdoenzyme biotin sulfoxide reductase (BisC) from E. coli, a close homologue of TorA 
(Table 1). The telling substitution of the second arginines by hydrophobic residues within the remnant twin-arginine motifs, and the peppering of the remnant ' $h$-regions' by acidic and polar residues, means that there is no argument that these $\mathrm{N}$-terminal peptides are Tat inactive and that the enzymes in question are definitely cytoplasmic in location. So what functions do these remnant signals have?

As with the A-class Tat signal peptides, the remnant signal peptides are most likely the primary binding sites for biosynthetic accessory proteins. Both in vivo bacterial twohybrid analysis (Vergnes et al., 2006) and in vitro calorimetry (Chan et al., 2006) have clearly demonstrated that the E. coli NarG remnant signal is recognized by, and bound directly to, the E. coli NarJ protein. The NarJ protein is essential for cellular NarG activity (Blasco et al., 1998) and, most strikingly, is distantly related to the bona fide twin-arginine signal peptide-binding proteins TorD and DmsD (Turner et al., 2004). Furthermore, NarJ binds to the NarG remnant signal with similar thermodynamics, and with a similar apparent dissociation constant $(160 \mathrm{nM})$, as TorD and DmsD bind to their respective A-class signal peptides (Hatzixanthis et al., 2005; Chan et al., 2006; Winstone et al., 2006). It is proposed here that the remnant signals are perhaps so closely related in structure and function to dualfunction (biosynthesis and targeting) A-class twin-arginine signal peptides that they should be grouped together as mono-function (biosynthesis only) C-class peptides (Table 1). Note that a biosynthetic chaperone for the remnant signal of the E. coli type III molybdoenzyme BisC has not yet been discovered. The genetic omission of this $\mathrm{C}$ class peptide, however, led to a complete loss of cellular biotin sulfoxide reductase activity (Ezraty et al., 2005), suggesting strongly that it plays a central role in assembly of this enzyme.

Type II molybdoenzymes are distributed throughout the prokaryotic kingdoms, including the archaea. The halophilic archaeon Haloferax mediterranei, for example, encodes a NarG-type respiratory nitrate reductase (Lledo et al., 2004). Most notably, however, $H$. mediterranei $\mathrm{NarG}$ is synthesized with an apparent $\mathrm{N}$-terminal twin-arginine signal peptide, pointing to the possible transport of NarGH to the extracytoplasmic side of the membrane in this archaeon (Table 1). Moreover, the NarG subunits of the archaea Pyrobaculum aerophilum, Archaeoglobus fulgidus and Haloarcula marismortui are also predicted to have Nterminal twin-arginine signal peptides (Table 1) (Afshar et al., 2001; Richardson et al., 2001; Yoshimatsu et al., 2007). It is possible that these archaeal signal peptides are not processed (Table 1), which may point to a role as $\mathrm{N}$ terminal signal anchors as has been suggested for the Tat signals of the bacterial Rieske proteins (Berks et al., 2005; Bachmann et al., 2006). Note, however, that both the $P$. aerophilum and A. fulgidus genomes do encode proteins (Pae0264 and Af1655, respectively) bearing some similarity to signal peptidases from Gram-positive eubacteria, suggesting that signal peptide cleavage is at least feasible in these organisms. Nevertheless, the presence of what appear to be intact twin-arginine signal peptides on archaeal NarG proteins serves to reinforce the hypothesis that eubacterial NarG proteins do indeed display N-terminal remnants of Tat signal peptides. In addition, it is important to recognize that NarJ chaperone proteins are also encoded by each of the archaeal nar gene-clusters discussed here. It is therefore very likely that these NarJ homologues will recognize and bind to their cognate NarG Tat signal peptides, and as a result all of the archaeal NarG twin-arginine signal peptides should provisionally fall into the dual-function A-class (Table 1).

With the apparent relationship between A-class and C-class peptides, especially through their chaperone-binding activities, it is tempting to consider further the $3 \mathrm{D}$ crystal structure of the C-class remnant signal from the E. coli NarG protein (Bertero et al., 2003). In the alternative crystal structure of the water-soluble (i.e. NarI-dissociated) NarGH dimer from E. coli, the remnant signal is exposed to solvent and completely disordered (Jormakka et al., 2004). This observation resonates with the limited structural analyses done on bona fide twin-arginine signal peptides, which show that these too are largely unstructured in aqueous solution (Kipping et al., 2003; San Miguel et al., 2003). In the NarGHI holoenzyme structure, however, the NarG remnant signal has some secondary structure comprising a 6 amino acid $\alpha$-helix at the $\mathrm{N}$-terminus, followed by a disordered region, and followed next by a twisted $\beta$-hairpin terminating at amino acid T-28 (Bertero et al., 2003; Fig. 5). This secondary structure must be induced in the holoenzyme by the extensive contacts made between the NarG remnant signal and NarI. Given that NarI is an integral membrane protein that contains an obvious binding site for a C-class remnant signal, it is tempting to speculate that the NarG:: NarI complex could be providing a tantalizing glimpse of what a TatC::twin-arginine signal peptide complex could look like immediately prior to the transport event (Fig. 5).

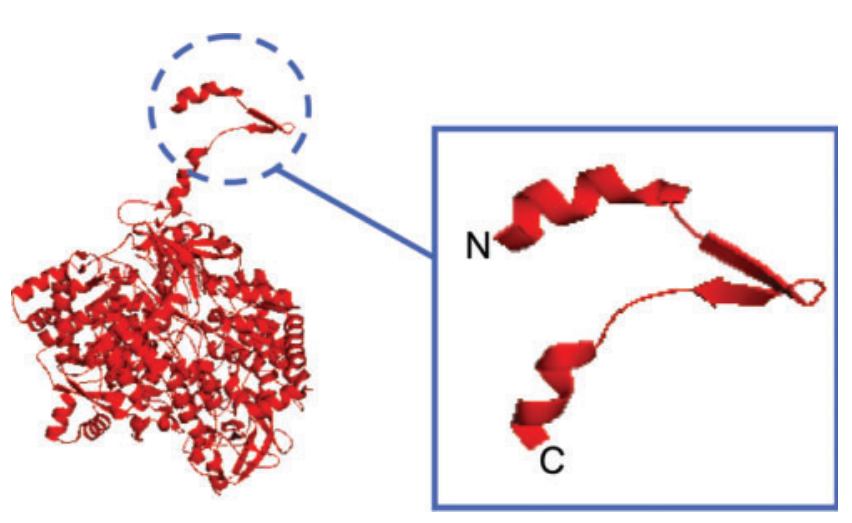

Fig. 5. Structure of the E. coli NarG remnant C-class signal when bound to Narl. The crystal structure of NarG showing, in close-up, the structure of the initial 28 amino acids that correspond to the C-class remnant signal peptide. 
Taken altogether, these observations point to an intimate evolutionary link between extracellular and cytoplasmic respiratory enzymes. Whether the ancient progenitor of the NarG proteins was originally located on the cell surface and subsequently relocated to the cytoplasm, or vice versa, during the course of evolution is a moot point, but one worth remembering if debating the evolution of the Tat pathway.

\section{....and diversity in the assembly of molybdoenzymes}

While the evidence for the existence of C-class remnant signals on some non-exported enzymes is compelling, this is not a universal feature amongst enzyme groups containing exported and non-exported homologues. The extremophilic deep-branching eubacterium Thermus thermophilus, for example, expresses a NarG-type nitrate reductase that is localized, together with its NarH partner, on the cytoplasmic face of the membrane attached to a complex comprising a NarI homologue and a membrane-bound cytochrome $c$ (NarC) (Zafra et al., 2005). The T. thermophilus NarG, however, contains a barely recognizable short $\mathrm{N}$-tail (Table 1), possibly just sufficient for the attachment of NarGH to NarIC, but not easily identifiable as a C-class remnant signal. Despite the lack of a clear C-class remnant signal, biosynthesis of T. thermophilus NarG remains strictly dependent upon a NarJ homologue (Zafra et al., 2005). This observation either suggests that the remaining $\mathrm{N}$-tail is sufficient for NarJ binding (note that the extreme Nterminal 15 amino acids of E. coli NarG was sufficient for NarJ binding in vitro: Chan et al., 2006) or points strongly towards the existence of a second NarJ-binding site on NarG. Indeed, the fact that the T. thermophilus NarGH dimer is already membrane-localized (presumably via a NarG N-tail interaction with NarIC) before NarJ-dependent maturation occurs suggests strongly that the second chaperone-binding site is functionally important and that NarJ is not bound to the N-tail (Zafra et al., 2005).

It is worth considering at this juncture that $E$. coli NarJ also binds to a second location on the E. coli NarG protein (Vergnes et al., 2006). Moreover, E. coli TorD also binds to at least one other location on the E. coli TorA protein, distinct from the A-class signal peptide, and this alternative binding site seems to be important for efficient cofactor loading (Ilbert et al., 2004; Jack et al., 2004). The location and sequence of the secondary chaperone-binding sites have not yet been identified for either system. However, given that TorD family proteins recognize specific peptide sequences, it seems most logical to assume that the amino acid sequence of any secondary binding sites should show some identity with the sequences of the respective $\mathrm{A}$-class and $\mathrm{C}$-class peptides.

The intimate link between TorD family chaperones and the type II and type III bis-MGD molybdoenzymes is genetically and biochemically unequivocal. But what about the assembly of type I bis-MGD enzymes? The type I bis-MGD molybdoprotein subfamily contains the Tat-dependent membrane-bound formate dehydrogenases (FdnGHI and FdoGHI in E. coli) and their non-exported cytoplasmic homologues (e.g. FdhF in E. coli). The type I subfamily also includes the periplasmic nitrate reductases (e.g. NapABCGH in E. coli) and, while a cytoplasmic homologue does not exist in E. coli, the related non-exported NarB-type assimilatory nitrate reductases which are widespread in other bacteria (Richardson et al., 2001). In all cases the nonexported cytoplasmic members of the type I subfamily do not display $\mathrm{N}$-tails or remnant signal peptides at all, which probably points both to a different evolutionary origin for these enzymes and governance by different biosynthetic principles. It is not yet known if TorD family proteins play any direct role in the assembly of type I molybdoenzymes. This is unlikely, however, since the genes encoding TorD homologues are only very rarely co-localized with those for type I molybdoenzymes. In the $\beta$-proteobacterium Azoarcus, for example, a gene encoding a TorD homologue (ebA2937) is found in a locus including various molybdoenzyme biosynthesis genes ( $m o b A, m o b B, f d h D)$ and the structural genes for a Tat-dependent respiratory formate dehydrogenase (ebA2936, ebA2935 and ebA2933) (Rabus et al., 2005).

The common denominator in the biosynthesis of extracellular type I molybdoenzymes may be the requirement for an $\mathrm{Fe}-\mathrm{S}$ cluster-containing ferredoxin accessory protein. The FdhE protein is consistently co-localized with gene clusters encoding Tat-dependent formate dehydrogenases. FdhE is known to be essential for the assembly of respiratory formate dehydrogenases and, most importantly, is not required for biosynthesis of the non-exported homologues (Mandrand-Berthelot et al., 1988; Paveglio et al., 1988; Schlindwein et al., 1990). While the FdnG and FdnH proteins appear to be completely absent from an $f d h E$ mutant (Mandrand-Berthelot et al., 1988), FdhE seems to be a specific chaperone for these Tat-dependent proteins rather than a transcriptional or translational regulator (Stewart et al., 1991). It is not known whether FdhE is a twin-arginine signal peptide-binding protein, or indeed whether it binds to the formate dehydrogenase at all, but FdhE is certainly not present in the crystallized holoenzyme (Jormakka et al., 2003). Sequence analysis suggests each FdhE polypeptide contains three conserved CxxC motifs (Turner et al., 2004), possibly indicative of the presence of $\mathrm{Fe}-\mathrm{S}$ clusters. Interestingly, this is a structural feature shared with an accessory protein $(\mathrm{NapF})$ that is required for the biosynthesis of the type I periplasmic nitrate reductase, NapA. The NapF protein has been shown recently to bind to the Tatdependent NapA precursor in the cell cytoplasm (Nilavongse et al., 2006) and its biochemical role would seem to be to catalyse the insertion of the single $\mathrm{Fe}-\mathrm{S}$ cluster into NapA prior to the export event (Olmo-Mira et al., 2004). Again, NapF-type proteins have never been shown to be required for the assembly of the related non-exported assimilatory nitrate reductases. The presence of $\mathrm{Fe}-\mathrm{S}$ clusters could point to roles in electron transfer for FdhE and NapF. 
While it is certainly possible that extracellular and cytoplasmic isoenzymes could be operating at vastly different redox potentials, which may necessitate a degree of 'reductive activation' of the periplasmic protein prior to export (e.g. Field et al., 2005; Zajicek et al., 2004), it is certainly not clear why denial of this activity would completely destabilize the enzymes in question (e.g. Mandrand-Berthelot et al., 1988).

In addition to NapF, genetic evidence suggests that a second accessory protein (NapD) is required for the biosynthesis of some periplasmic nitrate reductases (Potter \& Cole, 1999; Nilavongse et al., 2006). NapD is a very small protein (usually $<100$ amino acids) and, in E. coli at least, has been found to be essential for the biosynthesis of NapA (Potter \& Cole, 1999). NapD does not interact at all with NapF, but does bind tightly to NapA in the cytoplasm prior to export (Nilavongse et al., 2006). Again, the precise locations of NapD and NapF binding to NapA are not known; however, their physiological role must be, as with the FdhE protein, specific for the biosynthesis of the Tat-dependent type I enzymes, as genes encoding these proteins are never colocalized with non-exported type I homologues. Indeed, examples of accessory proteins required for the assembly of non-exported type I molybdoenzymes are few and far between. The NarM protein is one such isolated example, and is required for the biosynthesis of assimilatory nitrate reductases in cyanobacteria (Maeda \& Omata, 2004). This suggests that some type I molybdoenzymes do not require the assistance of a biosynthetic chaperone at all, at least for the 'insertion' of the cofactor, and some heterologous expression studies of type I enzymes from Salmonella suggest that dedicated Tat proofreading chaperones may also be dispensed with (Hensel et al., 1999; Hinsley \& Berks, 2002).

The type I, II and III bis-MGD enzymes are members of what was originally classified as 'the DMSO reductase family' of molybdenum and tungsten enzymes (Kisker et al., 1997). In addition to this group, a huge array of other molybdenumand tungsten-dependent enzymes have been identified in nature and these can be sorted into another three large families: 'the sulfite oxidase ( $\mathrm{SO}$ ) family'; 'the xanthine oxidase (XO) family'; and 'the aldehyde : ferredoxin oxidoreductase (AOR) family' (Kisker et al., 1997).

Members of the SO family bind a single molecule of the MPT form of the molybdenum cofactor, as opposed to the dinucleotide form, and include the cytoplasmic NADHdependent assimilatory nitrate reductases from plants and fungi (e.g. Fischer et al., 2005), and the periplasmic YedY protein from E. coli (Loschi et al., 2004). YedY is synthesized with a (long) twin-arginine signal peptide and is thought to associate with an unusual membrane-bound haemoprotein (YedZ) following translocation (von Rozycki et al., 2004; Brokx et al., 2005). YedY is apparently not a sulfite oxidase nor a nitrate reductase but a very unusual TMAO reductase (Loschi et al., 2004), and there are no known signal peptidebinding proteins required for its biosynthesis.
Members of the XO family are found in all kingdoms of life and bind a single molecule of MPT or, perhaps more commonly in the prokaryotic world, a single molecule of molybdopterin cytosine dinucleotide (MCD) (Kisker et al., 1997). Examples include the crystallographically defined carbon monoxide dehydrogenase from the $\alpha$-proteobacterium Oligotropha carboxidovorans (Dobbek et al., 1999), which contains MCD, and the xanthine dehydrogenase from Rhodobacter capsulatus (Leimkuhler et al., 1998; Truglio et al., 2002), which contains MPT as cofactor. The genes encoding the three-subunit $O$. carboxidovorans carbon monoxide dehydrogenase are encoded on a megaplasmid by a large gene cluster containing 12 genes - coxBCMSLDEFGHIK (Santiago et al., 1999). Of these, the CoxF protein is probably the most important in terms of biosynthesis since it belongs to the $\mathrm{XdhC}$ family (Leimkuhler \& Klipp, 1999). XdhC is an accessory protein which binds to the apo-form of the molybdoenzyme subunit (XdhB) of R. capsulatus xanthine dehydrogenase (Neumann et al., 2006), and its role seems to be akin to that originally described for TorD and NarJ (Blasco et al., 1998; Pommier et al., 1998) in that it may maintain $\mathrm{XdhB}$ in an 'open conformation' during cofactor insertion. Arguably the most important feature of $\mathrm{XdhC}$, however, is that this accessory protein does actually bind the molybdenum cofactor directly (Neumann et al., 2006).

Both the O. carboxidovorans and $R$. capsulatus XO family enzymes described above are cytoplasmically located and have no hints even of remnant C-class peptides to which $\mathrm{XdhC}$ proteins might attach. However, the E. coli genome does encode $\mathrm{XO}$ family members that may be transported to the periplasm via the Tat pathway. The E. coli yagPQRST cluster encodes a putative MCD-binding subunit (YagR) that, by analogy with carbon monoxide dehydrogenases, should associate with a flavoprotein (YagS) and an Fe-S protein (YagT) to form the holoenzyme (Berks et al., 2003). In this case the YagT $\mathrm{Fe}-\mathrm{S}$ protein, rather than the molybdoprotein, bears a twin-arginine signal peptide at its N-terminus (Berks et al., 2003). As a result, if YagRST is indeed transported to the periplasm it must be via a single signal peptide and as a fully assembled trimer - surely such a scenario would require a Tat proofreading chaperone?

The YagQ protein is a member of the XdhC family and is therefore dedicated to the insertion of the MCD cofactor into YagR (Neumann et al., 2006), which leaves YagP as a possible candidate, a 136 amino acid water-soluble protein that has been annotated as a putative transcriptional regulator in the databases but whose function clearly awaits further experimentation. The E. coli genome encodes two other YagR homologues that have been implicated in purine catabolism, XdhA (b2866) and XdhD (b2881) (Xi et al., 2000). Neither contains a twin-arginine signal peptide and neither is predicted to associate with partner proteins that possess Tat signal peptides. Moreover, there are also no obvious XdhC homologues encoded at these loci. 
Finally, members of the aldehyde:ferredoxin reductase (AOR) family were originally identified in hyperthermophilic archaea, where tungsten is often substituted for molybdenum in the active site (Kisker et al., 1997). The biosynthesis of this class of molybdoprotein has not been studied; however, the enzymes themselves have proven tractable to structural projects (Kisker et al., 1997). AOR family enzymes are usually monomeric proteins (or oligomers of identical subunits) that bind a single $\mathrm{Fe}-\mathrm{S}$ cluster as well as a single tungsten atom ligated by two MPT (not dinucleotide) cofactors (Kisker et al., 1997). As the name suggests, these enzymes usually couple the oxidation of aldehydes (or related compounds) to the reduction of a ferredoxin in the cell cytoplasm. Interestingly, the E. coli genome encodes a member of the AOR family, termed $\mathrm{YdhV}$, which is encoded in a putative operon containing six genes - ydhYVWXUT. YdhV does not bear a twinarginine signal peptide. The roles of the YdhW and YdhT proteins are difficult to predict from sequence alone; however, both YdhY and YdhX are predicted to be ferredoxins which could, in principle, receive electrons from the YdhV subunit. However, YdhX does, in fact, contain an $\mathrm{N}$-terminal Tat targeting signal (Berks et al., 2005). Moreover, YdhU is predicted to be an integral membrane cytochrome of the PhsC class normally associated with periplasmically oriented, Tat-dependent and molybdenum-dependent thiosulfate reductases (e.g. Hinsley \& Berks, 2002). This is certainly suggestive that YdhX could associate with YdhU at the periplasmic side of the membrane, but is the YdhV AOR family protein also periplasmic and translocated in tandem with YdhX? Only experimentation will reveal the answer, though it is tempting to speculate that this enzyme could be located on both sides of the membrane depending on which ferredoxin partner is attached, as reported for a Tattargeted catalase in Helicobacter pylori (Harris \& Hazell, 2003).

\section{Concluding remarks}

While this review has focused on recent advances in the understanding of how some prokaryotic molybdoenzymes are assembled, it is fair to say that this research just scratches the surface in terms of the overall diversity and complexity of post-translational biosynthetic processes. Studies of Fe-S cluster assembly, which can almost be classified as a 'housekeeping' biochemical process, form a vibrant research area that straddles both prokaryotic (Böck et al., 2006; Johnson et al., 2005) and eukaryotic systems (Balk \& Lobreaux, 2005; Lill \& Mühlenhoff, 2005). Of course, the assembly and insertion of $\mathrm{Fe}-\mathrm{S}$ clusters must be coordinated with many of the molybdoenzyme-specific processes outlined above. Moreover, cytochrome $c$ biogenesis (Stevens et al., 2004) and nickel-dependent enzyme assembly (Böck et al., 2006; Mulrooney \& Hausinger, 2003) are another two large research fields that in some cases must also dovetail considerably with the molydoenzyme systems described here. Finally, it is possible that pressure from the biotechnology and biomedical sectors will inspire research into biosynthesis of oft-overlooked, but potentially extremely important, complex enzyme systems such as the cobalamin-dependent reductive dehalogenases (Janssen et al., 2001), and the pyrroloquinoline quinone (PQQ)dependent dehydrogenases (Anthony, 2004).

\section{ACKNOWLEDGEMENTS}

I dedicate the 2006 Fleming Prize Lecture to my wife Tracy Palmer and our boys James and Jack. I would like to thank the University of East Anglia, and in particular David J. Richardson, for supporting and mentoring me in my early years as a group leader. I would also like to thank Ben Berks (Oxford) for guidance, support and many useful discussions. For stimulating collaborations I should acknowledge Arthur Oubrie (NV Organon), Ray Turner (Calgary), Lynne Macaskie (Birmingham), Geerten Vuister (Nijmegen) and Chris Spronk (Nijmegen). The postdocs, graduate students and technical staff who have worked with me over the last 6 years have all contributed something to this prize award and deserve special mention here - Judith Mayne, Verity Lyall, Alex Dubini, Kostas Hatzixanthis, Kev Moore, Julien Maillard, Karolina Förnvik, Iris Lüke, Bérengère Ize, Isabelle Caldelari and Dave Guymer. Thanks also to everyone in Tracy Palmer's and Ben Berks' research teams, especially Grant Buchanan and Rachael Jack, for discussions, ideas and contributions to original research papers. I would finally like to acknowledge The Royal Society, the BBSRC and the John and Pamela Salter Charitable Trust for financial support. I look forward now to new challenges at the University of Dundee.

\section{REFERENCES}

Afshar, S., Johnson, E., de Vries, S. \& Schröder, I. (2001). Properties of a thermostable nitrate reductase from the hyperthermophilic archaeon Pyrobaculum aerophilum. J Bacteriol 183, 5491-5495.

Alami, M., Lüke, I., Deitermann, S., Eisner, G., Koch, H. G., Brunner, J. \& Müller, M. (2003). Differential interactions between a twin-arginine signal peptide and its translocase in Escherichia coli. Mol Cell 12, 937-946.

Alder, N. N. \& Theg, S. M. (2003). Energetics of protein transport across biological membranes. a study of the thylakoid $\Delta \mathrm{pH}$ dependent/cpTat pathway. Cell 112, 231-242.

Anthony, C. (2004). The quinoprotein dehydrogenases for methanol and glucose. Arch Biochem Biophys 428, 2-9.

Aravind, L. \& Koonin, E. V. (1998a). A novel family of predicted phosphoesterases includes Drosophila prune protein and bacterial RecJ exonuclease. Trends Biochem Sci 23, 17-19.

Aravind, L. \& Koonin, E. V. (1998b). Phosphoesterase domains associated with DNA polymerases of diverse origins. Nucleic Acids Res 26, 3746-3752.

Aravind, L. \& Koonin, E. V. (1998c). The HD domain defines a new superfamily of metal-dependent phosphohydrolases. Trends Biochem Sci 23, 469-472.

Bachmann, J., Bauer, B., Zwicker, K., Ludwig, B. \& Anderka, O. (2006). The Rieske protein from Paracoccus denitrificans is inserted into the cytoplasmic membrane by the twin-arginine translocase. FEBS J 273, 4817-4830.

Balk, J. \& Lobreaux, S. (2005). Biogenesis of iron-sulfur proteins in plants. Trends Plant Sci 10, 324-331. 
Behrendt, J., Standar, K., Lindenstrauss, U. \& Brüser, T. (2004). Topological studies on the twin-arginine translocase component TatC. FEMS Microbiol Lett 234, 303-308.

Bendtsen, J. D., Nielsen, H., Widdick, D. A., Palmer, T. \& Brünak, S. (2005). Prediction of twin-arginine signal peptides. $B M C$ Bioinformatics 6, 167.

Berks, B. C. (1996). A common export pathway for proteins binding complex redox cofactors? Mol Microbiol 22, 393-404.

Berks, B. C., Ferguson, S. J., Moir, J. W. \& Richardson, D. J. (1995). Enzymes and associated electron transport systems that catalyse the respiratory reduction of nitrogen oxides and oxyanions. Biochim Biophys Acta 1232, 97-173.

Berks, B. C., Palmer, T. \& Sargent, F. (2003). The Tat protein translocation pathway and its role in microbial physiology. $A d v$ Microb Physiol 47, 187-254.

Berks, B. C., Palmer, T. \& Sargent, F. (2005). Protein targeting by the bacterial twin-arginine translocation (Tat) pathway. Curr Opin Microbiol 8, 174-181.

Bernhard, M., Schwartz, E., Rietdorf, J. \& Friedrich, B. (1996). The Alcaligenes eutrophus membrane-bound hydrogenase gene locus encodes functions involved in maturation and electron transport coupling. J Bacteriol 178, 4522-4529.

Bertero, M. G., Rothery, R. A., Palak, M., Hou, C., Lim, D., Blasco, F., Weiner, J. H. \& Strynadka, N. C. (2003). Insights into the respiratory electron transfer pathway from the structure of nitrate reductase A. Nat Struct Biol 10, 681-687.

Bilous, P. T., Cole, S. T., Anderson, W. F. \& Weiner, J. H. (1988). Nucleotide sequence of the $d m s A B C$ operon encoding the anaerobic dimethyl sulphoxide reductase of Escherichia coli. Mol Microbiol 2, 785-795.

Blasco, F., Dos Santos, J.-P., Magalon, A., Frixon, C., Guigliarelli, B., Santini, C.-L. \& Giordano, G. (1998). NarJ is a specific chaperone required for molybdenum cofactor assembly in nitrate reductase A of Escherichia coli. Mol Microbiol 28, 435-447.

Böck, A., King, P. W., Blokesch, M. \& Posewitz, M. C. (2006). Maturation of hydrogenases. Adv Microb Physiol 51, 1-71.

Bogsch, E. G., Sargent, F., Stanley, N. R., Berks, B. C., Robinson, C. \& Palmer, T. (1998). An essential component of a novel bacterial protein export system with homologues in plastids and mitochondria. J Biol Chem 273, 18003-18006.

Bolhuis, A. (2002). Protein transport in the halophilic archaeon Halobacterium sp. NRC-1: a major role for the twin-arginine translocation pathway? Microbiology 148, 3335-3346.

Bolhuis, A., Mathers, J. E., Thomas, J. D., Barrett, C. M. \& Robinson, C. (2001). TatB and TatC form a functional and structural unit of the twin-arginine translocase from Escherichia coli. J Biol Chem 276, 20213-20219.

Brokx, S. J., Rothery, R. A., Zhang, G., Ng, D. P. \& Weiner, J. H. (2005). Characterization of an Escherichia coli sulfite oxidase homologue reveals the role of a conserved active site cysteine in assembly and function. Biochemistry 44, 10339-10348.

Buchanan, G., Küper, J., Mendel, R. R., Schwarz, G. \& Palmer, T. (2001). Characterisation of the mob locus of Rhodobacter sphaeroides WS8: $m o b A$ is the only gene required for molybdopterin guanine dinucleotide synthesis. Arch Microbiol 176, 62-68.

Butland, G., Zhang, J. W., Yang, W., Sheung, A., Wong, P., Greenblatt, J. F., Emili, A. \& Zamble, D. B. (2006). Interactions of the Escherichia coli hydrogenase biosynthetic proteins: HybG complex formation. FEBS Lett 580, 677-681.

Chaddock, A. M., Mant, A., Karnauchov, I., Brink, S., Herrmann, R. G., Klösgen, R.-B. \& Robinson, C. (1995). A new type of signal peptide: central role of a twin-arginine motif in transfer signals for the delta $\mathrm{pH}$-dependent thylakoidal protein translocase. EMBO J 14, 2715-2722.

Chan, C. S., Howell, J. M., Workentine, M. L. \& Turner, R. J. (2006). Twin-arginine translocase may have a role in the chaperone function of NarJ from Escherichia coli. Biochem Biophys Res Commun 343, 244-251.

Chanal, A., Santini, C.-L. \& Wu, L.-F. (1998). Potential receptor function of three homologous components, TatA, TatB and TatE, of the twin-arginine signal sequence-dependent metalloenzyme translocation pathway in Escherichia coli. Mol Microbiol 30, 674-676.

Chou, Y. T. \& Gierasch, L. M. (2005). The conformation of a signal peptide bound by Escherichia coli preprotein translocase SecA. J Biol Chem 280, 32753-32760.

Creighton, A. M., Hulford, A., Mant, A., Robinson, D. \& Robinson, C. (1995). A monomeric, tightly folded stromal intermediate on the delta $\mathrm{pH}$-dependent thylakoidal protein transport pathway. J Biol Chem 270, 1663-1669.

Czjzek, M., Dos Santos, J.-P., Pommier, J., Giordano, G., Mejean, V. \& Haser, R. (1998). Crystal structure of oxidized trimethylamine $\mathrm{N}$ oxide reductase from Shewanella massilia at $2.5 \AA$ resolution. J Mol Biol 284, 435-447.

Dabney-Smith, C., Mori, H. \& Cline, K. (2006). Oligomers of Tha4 organize at the thylakoid Tat translocase during protein transport. J Biol Chem 281, 5476-5483.

Dekker, N., Cox, R. C., Kramer, R. A. \& Egmond, M. R. (2001). Substrate specificity of the integral membrane protease OmpT determined by spatially addressed peptide libraries. Biochemistry 40, 1694-1701.

de Leeuw, E., Granjon, T., Porcelli, I., Alami, M., Carr, S. B., Müller, M., Sargent, F., Palmer, T. \& Berks, B. C. (2002). Oligomeric properties and signal peptide binding by Escherichia coli Tat protein transport complexes. J Mol Biol 322, 1135-1146.

Delisa, M. P., Tullman, D. \& Georgiou, G. (2003). Folding quality control in the export of proteins by the bacterial twin-arginine translocation pathway. Proc Natl Acad Sci U S A 100, 6115-6120.

Dilks, K., Rose, R. W., Hartmann, E. \& Pohlschröder, M. (2003). Prokaryotic utilization of the twin-arginine translocation pathway: a genomic survey. J Bacteriol 185, 1478-1483.

Dobbek, H., Gremer, L., Meyer, O. \& Huber, R. (1999). Crystal structure and mechanism of CO dehydrogenase, a molybdo ironsulfur flavoprotein containing S-selanylcysteine. Proc Natl Acad Sci U S A 96, 8884-8889.

Doudna, J. A. \& Batey, R. T. (2004). Structural insights into the signal recognition particle. Annu Rev Biochem 73, 539-557.

Dreusch, A., Bürgisser, D. M., Heizmann, C. W. \& Zumft, W. G. (1997). Lack of copper insertion into unprocessed cytoplasmic nitrous oxide reductase generated by an R20D substitution in the arginine consensus motif of the signal peptide. Biochim Biophys Acta 1319, 311-318.

Drew, D., Sjostrand, D., Nilsson, J., Urbig, T., Chin, C. N., de Gier, J. W. \& von Heijne, G. (2002). Rapid topology mapping of Escherichia coli inner-membrane proteins by prediction and PhoA/GFP fusion analysis. Proc Natl Acad Sci U S A 99, 2690-2695.

Dridge, E. J., Richardson, D. J., Lewis, R. J. \& Butler, C. S. (2006). Developing structure-based models to predict substrate specificity of D-group (type II) molybdenum enzymes: application to a molybdoenzyme of unknown function from Archaeoglobus fulgidus. Biochem Soc Trans 34, 118-121.

Dubini, A. \& Sargent, F. (2003). Assembly of Tat-dependent [NiFe] hydrogenases: identification of precursor-binding accessory proteins. FEBS Lett 549, 141-146.

Ellis, R. J. \& Hartl, F. U. (1999). Principles of protein folding in the cellular environment. Curr Opin Struct Biol 9, 102-110. 
Enoch, H. G. \& Lester, R. L. (1975). The purification and properties of formate dehydrogenase and nitrate reductase from Escherichia coli. J Biol Chem 250, 6693-6705.

Ezraty, B., Bos, J., Barras, F. \& Aussel, L. (2005). Methionine sulfoxide reduction and assimilation in Escherichia coli: new role for the biotin sulfoxide reductase BisC. J Bacteriol 187, 231-237.

Field, S. J., Thornton, N. P., Anderson, L. J., Gates, A. J., Reilly, A., Jepson, B. J., Richardson, D. J., George, S. J., Cheesman, M. R. \& Butt, J. N. (2005). Reductive activation of nitrate reductases. Dalton Trans 3580-3586.

Finazzi, G., Chasen, C., Wollman, F. A. \& de Vitry, C. (2003). Thylakoid targeting of Tat passenger proteins shows no $\Delta \mathrm{pH}$ dependence in vivo. EMBO J 22, 807-815.

Fischer, K., Barbier, G. G., Hecht, H. J., Mendel, R. R., Campbell, W. H. \& Schwarz, G. (2005). Structural basis of eukaryotic nitrate reduction: crystal structures of the nitrate reductase active site. Plant Cell 17, 1167-1179.

Focia, P. J., Shepotinovskaya, I. V., Seidler, J. A. \& Freymann, D. M. (2004). Heterodimeric GTPase core of the SRP targeting complex. Science 303, 373-377.

Friedrich, B., Hogrefe, C. \& Schlegel, H. G. (1981). Naturally occurring genetic transfer of hydrogen-oxidizing ability between strains of Alcaligenes eutrophus. J Bacteriol 147, 198-205.

Galperin, M. Y., Nikolskaya, A. N. \& Koonin, E. V. (2001). Novel domains of the prokaryotic two-component signal transduction systems. FEMS Microbiol Lett 203, 11-21.

Genest, O., Ilbert, M., Mejean, V. \& Iobbi-Nivol, C. (2005). TorD, an essential chaperone for TorA molybdoenzyme maturation at high temperature. J Biol Chem 280, 15644-15648.

Genest, O., Seduk, F., Ilbert, M., Mejean, V. \& lobbi-Nivol, C. (2006a). Signal peptide protection by specific chaperone. Biochem Biophys Res Commun 339, 991-995.

Genest, O., Seduk, F., Theraulaz, L., Mejean, V. \& Iobbi-Nivol, C. (2006b). Chaperone protection of immature molybdoenzyme during molybdenum cofactor limitation. FEMS Microbiol Lett 265, 51-55.

Gohlke, U., Pullan, L., McDevitt, C. A., Porcelli, I., de Leeuw, E., Palmer, T., Saibil, H. R. \& Berks, B. C. (2005). The TatA component of the twin-arginine protein transport system forms channel complexes of variable diameter. Proc Natl Acad Sci U S A 102, 10482-10486.

Gralnick, J. A., Vali, H., Lies, D. P. \& Newman, D. K. (2006). Extracellular respiration of dimethyl sulfoxide by Shewanella oneidensis strain MR-1. Proc Natl Acad Sci U S A 103, 4669-4674.

Harris, A. G. \& Hazell, S. L. (2003). Localisation of Helicobacter pylori catalase in both the periplasm and cytoplasm, and its dependence on the twin-arginine target protein, KapA, for activity. FEMS Microbiol Lett 229, 283-289.

Hatzixanthis, K., Palmer, T. \& Sargent, F. (2003). A subset of bacterial inner membrane proteins integrated by the twin-arginine translocase. Mol Microbiol 49, 1377-1390.

Hatzixanthis, K., Clarke, T. A., Oubrie, A., Richardson, D. J., Turner, R. J. \& Sargent, F. (2005). Signal peptide-chaperone interactions on the twin-arginine protein transport pathway. Proc Natl Acad Sci U S A 102, 8460-8465.

Hensel, M., Hinsley, A. P., Nikolaus, T., Sawers, G. \& Berks, B. C. (1999). The genetic basis of tetrathionate respiration in Salmonella typhimurium. Mol Microbiol 32, 275-287.

Hinsley, A. P. \& Berks, B. C. (2002). Specificity of respiratory pathways involved in the reduction of sulfur compounds by Salmonella enterica. Microbiology 148, 3631-3638.

Hynds, P. J., Robinson, D. \& Robinson, C. (1998). The Secindependent twin-arginine translocation system can transport both tightly folded and malfolded proteins across the thylakoid membrane. J Biol Chem 273, 34868-34874.

Ilbert, M., Mejean, V., Giudici-Orticoni, M. T., Samama, J.-P. \& lobbi-Nivol, C. (2003). Involvement of a mate chaperone (TorD) in the maturation pathway of molybdoenzyme TorA. J Biol Chem 278, 28787-28792.

Ilbert, M., Mejean, V. \& Iobbi-Nivol, C. (2004). Functional and structural analysis of members of the TorD family, a large chaperone family dedicated to molybdoproteins. Microbiology 150, 935-943.

Jack, R. L., Buchanan, G., Dubini, A., Hatzixanthis, K., Palmer, T. \& Sargent, F. (2004). Coordinating assembly and export of complex bacterial proteins. EMBO J 23, 3962-3972.

Jack, R. L., Dubini, A., Palmer, T. \& Sargent, F. (2005). Common principles in the biosynthesis of diverse enzymes. Biochem Soc Trans 33, 105-107.

Janssen, D. B., Oppentocht, J. E. \& Pölarends, G. J. (2001). Microbial dehalogenation. Curr Opin Biotechnol 12, 254-258.

Johnson, J. L., Indermaur, L. W. \& Rajagopalan, K. V. (1991). Molybdenum cofactor biosynthesis in Escherichia coli. Requirement of the chlB gene product for the formation of molybdopterin guanine dinucleotide. J Biol Chem 266, 12140-12145.

Johnson, D. C., Dean, D. R., Smith, A. D. \& Johnson, M. K. (2005). Structure, function, and formation of biological iron-sulfur clusters. Annu Rev Biochem 74, 247-281.

Jongbloed, J. D., van der Ploeg, R. \& van Dijl, J.-M. (2006). Bifunctional TatA subunits in minimal Tat protein translocases. Trends Microbiol 14, 2-4.

Jormakka, M., Tornröth, S., Byrne, B. \& Iwata, S. (2002). Molecular basis of proton motive force generation: structure of formate dehydrogenase-N. Science 295, 1863-1868.

Jormakka, M., Byrne, B. \& Iwata, S. (2003). Protonmotive force generation by a redox loop mechanism. FEBS Lett 545, 25-30.

Jormakka, M., Richardson, D. J., Byrne, B. \& Iwata, S. (2004). Architecture of NarGH reveals a structural classification of MobisMGD enzymes. Structure 12, 95-104.

Khangulov, S. V., Gladyshev, V. N., Dismukes, G. C. \& Stadtman, T. C. (1998). Selenium-containing formate dehydrogenase-H from Escherichia coli: a molybdopterin enzyme that catalyzes formate oxidation without oxygen transfer. Biochemistry 37, 3518-3528.

Ki, J. J., Kawarasaki, Y., Gam, J., Harvey, B. R., Iverson, B. L. \& Georgiou, G. (2004). A periplasmic fluorescent reporter protein and its application in high-throughput membrane protein topology analysis. J Mol Biol 341, 901-909.

Kipping, M., Lilie, H., Lindenstrauss, U., Andreesen, J. R., Griesinger, C., Carlomagno, T. \& Brüser, T. (2003). Structural studies on a twin-arginine signal sequence. FEBS Lett 550, 18-22.

Kisker, C., Schindelin, H. \& Rees, D. C. (1997). Molybdenumcofactor-containing enzymes: structure and mechanism. Annu Rev Biochem 66, 233-267.

Koonin, E. V. (1996). A duplicated catalytic motif in a new superfamily of phosphohydrolases and phospholipid synthases that includes poxvirus envelope proteins. Trends Biochem Sci 21, 242-243.

Lee, P. A., Orriss, G. L., Buchanan, G., Greene, N. P., Bond, P. J., Punginelli, C., Jack, R. L., Sansom, M. S., Berks, B. C. \& Palmer, T. (2006). Cysteine-scanning mutagenesis and disulfide mapping studies of the conserved domain of the twin-arginine translocase TatB component. J Biol Chem 281, 34072-34085.

Leimkuhler, S. \& Klipp, W. (1999). Role of XdhC in molybdenum cofactor insertion into xanthine dehydrogenase of Rhodobacter capsulatus. J Bacteriol 181, 2745-2751. 
Leimkuhler, S., Kern, M., Solomon, P. S., McEwan, A. G., Schwarz, G., Mendel, R. R. \& Klipp, W. (1998). Xanthine dehydrogenase from the phototrophic purple bacterium Rhodobacter capsulatus is more similar to its eukaryotic counterparts than to prokaryotic molybdenum enzymes. Mol Microbiol 27, 853-869.

Li, S. Y., Chang, B. Y. \& Lin, S. C. (2006). Coexpression of TorD enhances the transport of GFP via the Tat pathway. J Biotechnol 122, 412-421.

Lill, R. \& Mühlenhoff, U. (2005). Iron-sulfur-protein biogenesis in eukaryotes. Trends Biochem Sci 30, 133-141.

Lledo, B., Martinez-Espinosa, R. M., Marhuenda-Egea, F. C. \& Bonete, M. J. (2004). Respiratory nitrate reductase from haloarchaeon Haloferax mediterranei: biochemical and genetic analysis. Biochim Biophys Acta 1674, 50-59.

Loschi, L., Brokx, S. J., Hills, T. L., Zhang, G., Bertero, M. G., Lovering, A. L., Weiner, J. H. \& Strynadka, N. C. (2004). Structural and biochemical identification of a novel bacterial oxidoreductase. J Biol Chem 279, 50391-50400.

Lubitz, S. P. \& Weiner, J. H. (2003). The Escherichia coli ynfEFGHI operon encodes polypeptides which are paralogues of dimethyl sulfoxide reductase (DmsABC). Arch Biochem Biophys 418, 205-216.

Maeda, S. \& Omata, T. (2004). A novel gene (narM) required for expression of nitrate reductase activity in the cyanobacterium Synechococcus elongatus strain PCC7942. J Bacteriol 186, $2107-$ 2114.

Mandrand-Berthelot, M.-A., Couchoux-Luthaud, G., Santini, C.-L. \& Giordano, G. (1988). Mutants of Escherichia coli specifically deficient in respiratory formate dehydrogenase activity. J Gen Microbiol 134, 3129-3139.

Mayer, M. P., Laufen, T., Paal, K., McCarty, J. S. \& Bukau, B. (1999). Investigation of the interaction between DnaK and DnaJ by surface plasmon resonance spectroscopy. J Mol Biol 289, 1131-1144.

McAlpine, A. S., McEwan, A. G. \& Bailey, S. (1998). The high resolution crystal structure of DMSO reductase in complex with DMSO. J Mol Biol 275, 613-623.

McCrindle, S. L., Kappler, U. \& McEwan, A. G. (2005). Microbial dimethylsulfoxide and trimethylamine- $N$-oxide respiration. $A d v$ Microb Physiol 50, 147-198.

McDevitt, C. A., Hugenholtz, P., Hanson, G. R. \& McEwan, A. G. (2002). Molecular analysis of dimethyl sulphide dehydrogenase from Rhodovulum sulfidophilum: its place in the dimethyl sulphoxide reductase family of microbial molybdopterin-containing enzymes. Mol Microbiol 44, 1575-1587.

McDevitt, C. A., Hicks, M. G., Palmer, T. \& Berks, B. C. (2005). Characterisation of Tat protein transport complexes carrying inactivating mutations. Biochem Biophys Res Commun 329, 693-698.

Mejean, V., lobbi-Nivol, C., Lepelletie, M., Giordano, G., Chippaux, M. \& Pascal, M. C. (1994). TMAO anaerobic respiration in Escherichia coli: involvement of the tor operon. Mol Microbiol 11, 1169-1179.

Mitchell, P. (1961). Coupling of phosphorylation to electron and hydrogen transfer by a chemiosmotic type of mechanism. Nature 191, 144-148.

Mitchell, P. \& Moyle, J. (1967). Chemiosmotic hypothesis of oxidative phophorylation. Nature 213, 137-139.

Mori, H. \& Cline, K. (2002). A twin arginine signal peptide and the $\mathrm{pH}$ gradient trigger reversible assembly of the thylakoid $\Delta \mathrm{pH} / \mathrm{Tat}$ translocase. J Cell Biol 157, 205-210.

Moriya, N., Minamino, T., Hughes, K. T., MacNab, R. M. \& Namba, K. (2006). The type III flagellar export specificity switch is dependent on FliK ruler and a molecular clock. J Mol Biol 359, 466-477.
Mulrooney, S. B. \& Hausinger, R. P. (2003). Nickel uptake and utilization by microorganisms. FEMS Microbiol Rev 27, 239261.

Neumann, M., Schulte, M., Junemann, N., Stocklein, W. \& Leimkuhler, S. (2006). Rhodobacter capsulatus XdhC is involved in molybdenum cofactor binding and insertion into xanthine dehydrogenase. J Biol Chem 281, 15701-15708.

Nilavongse, A., Brondijk, T. H., Overton, T. W., Richardson, D. J., Leach, E. R. \& Cole, J. A. (2006). The NapF protein of the Escherichia coli periplasmic nitrate reductase system: demonstration of a cytoplasmic location and interaction with the catalytic subunit, NapA. Microbiology 152, 3227-3237.

Nivière, V., Wong, S. L. \& Voordouw, G. (1992). Site-directed mutagenesis of the hydrogenase signal peptide consensus box prevents export of a $\beta$-lactamase fusion protein. J Gen Microbiol 138, 2173-2183.

Oates, J., Mathers, J., Mangels, D., Kühlbrandt, W., Robinson, C. \& Model, K. (2003). Consensus structural features of purified bacterial TatABC complexes. J Mol Biol 330, 277-286.

Oates, J., Barrett, C. M., Barnett, J. P., Byrne, K. G., Bolhuis, A. \& Robinson, C. (2005). The Escherichia coli twin-arginine translocation apparatus incorporates a distinct form of TatABC complex, spectrum of modular TatA complexes and minor TatAB complex. J Mol Biol 346, 295-305.

Olmo-Mira, M. F., Gavira, M., Richardson, D. J., Castillo, F., Moreno-Vivian, C. \& Roldan, M. D. (2004). NapF is a cytoplasmic iron-sulfur protein required for $\mathrm{Fe}-\mathrm{S}$ cluster assembly in the periplasmic nitrate reductase. J Biol Chem 279, 49727-49735.

Oresnik, I. J., Ladner, C. L. \& Turner, R. J. (2001). Identification of a twin-arginine leader-binding protein. Mol Microbiol 40, 323-331.

Palmer, T. \& Berks, B. C. (2003). Moving folded proteins across the bacterial cell membrane. Microbiology 149, 547-556.

Papish, A. L., Ladner, C. L. \& Turner, R. J. (2003). The twin-arginine leader-binding protein, DmsD, interacts with the TatB and TatC subunits of the Escherichia coli twin-arginine translocase. J Biol Chem 278, 32501-32506.

Paveglio, M. T., Tang, J. S., Unger, R. E. \& Barrett, E. L. (1988). Formate-nitrate respiration in Salmonella typhimurium: studies of two rha-linked $f d n$ genes. J Bacteriol 170, 213-217.

Pierson, D. E. \& Campbell, A. (1990). Cloning and nucleotide sequence of bis $C$, the structural gene for biotin sulfoxide reductase in Escherichia coli. J Bacteriol 172, 2194-2198.

Pommier, J., Mejean, V., Giordano, G. \& Iobbi-Nivol, C. (1998). TorD, a cytoplasmic chaperone that interacts with the unfolded trimethylamine $\mathrm{N}$-oxide reductase enzyme (TorA) in Escherichia coli. $J$ Biol Chem 273, 16615-16620.

Pop, O., Martin, U., Abel, C. \& Müller, J. P. (2002). The twin-arginine signal peptide of $\mathrm{PhoD}$ and the TatAd/Cd proteins of Bacillus subtilis form an autonomous Tat translocation system. J Biol Chem 277, 3268-3273.

Porcelli, I., de Leeuw, E., Wallis, R., van den Brink-van der Laan, E., de Kruijff, B., Wallace, B. A., Palmer, T. \& Berks, B. C. (2002). Characterization and membrane assembly of the TatA component of the Escherichia coli twin-arginine protein transport system. Biochemistry 41, 13690-13697.

Potter, L. C. \& Cole, J. A. (1999). Essential roles for the products of the napABCD genes, but not napFGH, in periplasmic nitrate reduction by Escherichia coli K-12. Biochem J 344, 69-76.

Rabus, R., Kübe, M., Heider, J., Beck, A., Heitmann, K., Widdel, F. \& Reinhardt, R. (2005). The genome sequence of an anaerobic aromatic-degrading denitrifying bacterium, strain EbN1. Arch Microbiol 183, 27-36. 
Ray, N., Oates, J., Turner, R. J. \& Robinson, C. (2003). DmsD is required for the biogenesis of DMSO reductase in Escherichia coli but not for the interaction of the DmsA signal peptide with the Tat apparatus. FEBS Lett 534, 156-160.

Richardson, D. J. (2000). Bacterial respiration: a flexible process for a changing environment. Microbiology 146, 551-571.

Richardson, D. J., Berks, B. C., Russell, D. A., Spiro, S. \& Taylor, C. J. (2001). Functional, biochemical and genetic diversity of prokaryotic nitrate reductases. Cell Mol Life Sci 58, 165-178.

Richter, S. \& Brüser, T. (2005). Targeting of unfolded PhoA to the Tat translocon of Escherichia coli. J Biol Chem 280, 42723-42730.

Rodrigue, A., Chanal, A., Beck, K., Müller, M. \& Wu, L.-F. (1999). Cotranslocation of a periplasmic enzyme complex by a hitchhiker mechanism through the bacterial Tat pathway. J Biol Chem 274, 13223-13228.

Rose, R. W., Brüser, T., Kissinger, J. C. \& Pohlschröder, M. (2002). Adaptation of protein secretion to extremely high-salt conditions by extensive use of the twin-arginine translocation pathway. Mol Microbiol 45, 943-950.

Rossmann, M. G., Liljas, A., Branden, C. I. \& Bansazak, L. J. (1975). Evolutionary relationships among dehydrogenases. In The Enzymes, vol. 11. Edited by I. P. D. Boyer. New York: Academic Press.

Rothery, R. A., Bertero, M. G., Cammack, R., Palak, M., Blasco, F., Strynadka, N. C. \& Weiner, J. H. (2004). The catalytic subunit of Escherichia coli nitrate reductase A contains a novel [4Fe-4S] cluster with a high-spin ground state. Biochemistry 43, 5324-5333.

Rubio, L. M., Flores, E. \& Herrero, A. (2002). Purification, cofactor analysis, and site-directed mutagenesis of Synechococcus ferredoxinnitrate reductase. Photosynth Res 72, 13-26.

Ryan, R. P., Fouhy, Y., Lucey, J. F., Crossman, L. C., Spiro, S., He, Y. W., Zhang, L. H., Heeb, S., Camara, M. \& other authors (2006). Cell-cell signaling in Xanthomonas campestris involves an HD-GYP domain protein that functions in cyclic di-GMP turnover. Proc Natl Acad Sci U S A 103, 6712-6717.

Sambasivarao, D., Turner, R. J., Simala-Grant, J. L., Shaw, G., Hu, J. \& Weiner, J. H. (2000). Multiple roles for the twin arginine leader sequence of dimethyl sulfoxide reductase of Escherichia coli. J Biol Chem 275, 22526-22531.

San Miguel, M., Marrington, R., Rodger, P. M., Rodger, A. \& Robinson, C. (2003). An Escherichia coli twin-arginine signal peptide switches between helical and unstructured conformations depending on the hydrophobicity of the environment. Eur J Biochem 270, 3345-3352.

Santiago, B., Schubel, U., Egelsee, C. \& Meyer, O. (1999). Sequence analysis, characterization and $\mathrm{CO}$-specific transcription of the cox gene cluster on the megaplasmid pHCG3 of Oligotropha carboxidovorans. Gene 236, 115-124.

Santini, C.-L., Ize, B., Chanal, A., Müller, M., Giordano, G. \& Wu, L.-F. (1998). A novel Sec-independent periplasmic protein translocation pathway in Escherichia coli. EMBO J 17, 101-112.

Sarfo, K. J., Winstone, T. L., Papish, A. L., Howell, J. M., Kadir, H., Vogel, H. J. \& Turner, R. J. (2004). Folding forms of Escherichia coli DmsD, a twin-arginine leader binding protein. Biochem Biophys Res Commun 315, 397-403.

Sargent, F., Bogsch, E. G., Stanley, N. R., Wexler, M., Robinson, C., Berks, B. C. \& Palmer, T. (1998a). Overlapping functions of components of a bacterial Sec-independent protein export pathway. EMBO J 17, 3640-3650.

Sargent, F., Ballantine, S. P., Rugman, P. A., Palmer, T. \& Boxer, D. H. (1998b). Reassignment of the gene encoding the Escherichia coli hydrogenase 2 small subunit - identification of a soluble precursor of the small subunit in a hypB mutant. Eur J Biochem 255, 746-754.
Sargent, F., Stanley, N. R., Berks, B. C. \& Palmer, T. (1999). Secindependent protein translocation in Escherichia coli: a distinct and pivotal role for the TatB protein. J Biol Chem 274, 36073-36082.

Sargent, F., Gohlke, U., de Leeuw, E., Stanley, N. R., Palmer, T., Saibil, H. R. \& Berks, B. C. (2001). Purified components of the Escherichia coli Tat protein transport system form a double-layered ring structure. Eur J Biochem 268, 3361-3367.

Sargent, F., Berks, B. C. \& Palmer, T. (2002). Assembly of membrane-bound respiratory complexes by the Tat protein-transport system. Arch Microbiol 178, 77-84

Sargent, F., Berks, B. C. \& Palmer, T. (2006). Pathfinders and trailblazers: a prokaryotic targeting system for transport of folded proteins. FEMS Microbiol Lett 254, 198-207.

Schindelin, H., Kisker, C., Hilton, J., Rajagopalan, K. V. \& Rees, D. C. (1996). Crystal structure of DMSO reductase: redox-linked changes in molybdopterin coordination. Science 272, 1615-1621.

Schlindwein, C., Giordano, G., Santini, C.-L. \& Mandrand, M.-A. (1990). Identification and expression of the Escherichia coli $f d h D$ and $f d h E$ genes, which are involved in the formation of respiratory formate dehydrogenase. J Bacteriol 172, 6112-6121.

Schneider, F., Lowe, J., Hüber, R., Schindelin, H., Kisker, C. \& Knablein, J. (1996). Crystal structure of dimethyl sulfoxide reductase from Rhodobacter capsulatus at $1.88 \AA$ resolution. J Mol Biol 263, 53-69.

Schwarz, G. (2005). Molybdenum cofactor biosynthesis and deficiency. Cell Mol Life Sci 62, 2792-2810.

Settles, A. M., Yonetani, A., Baron, A., Bush, D. R., Cline, K. \& Martienssen, R. (1997). Sec-independent protein translocation by the maize Hcf106 protein. Science 278, 1467-1470.

Shaw, A. L., Leimkuhler, S., Klipp, W., Hanson, G. R. \& McEwan, A. G. (1999). Mutational analysis of the dimethyl sulfoxide respiratory (dor) operon of Rhodobacter capsulatus. Microbiology 145, 1409-1420.

Soballe, B. \& Poole, R. K. (1999). Microbial ubiquinones: multiple roles in respiration, gene regulation and oxidative stress management. Microbiology 145, 1817-1830.

Stan, T., Ahting, U., Dembowski, M., Kunkele, K. P., Nussberger, S., Neupert, W. \& Rapaport, D. (2000). Recognition of preproteins by the isolated TOM complex of mitochondria. EMBO J 19, 4895-4902.

Stanley, N. R., Sargent, F., Buchanan, G., Shi, J., Stewart, V., Palmer, T. \& Berks, B. C. (2002). Behaviour of topological marker proteins targeted to the Tat protein transport pathway. Mol Microbiol 43, 1005-1021.

Stevens, J. M., Daltrop, O., Allen, J. W. \& Ferguson, S. J. (2004). Ctype cytochrome formation: chemical and biological enigmas. Acc Chem Res 37, 999-1007.

Stewart, V., Lin, J. T. \& Berg, B. L. (1991). Genetic evidence that genes $f d h D$ and $f d h E$ do not control synthesis of formate dehydrogenase-N in Escherichia coli K-12. J Bacteriol 173, 4417-4423.

Temple, C. A. \& Rajagopalan, K. V. (2000). Mechanism of assembly of the bis(molybdopteringuanine dinucleotide) molybdenum cofactor in Rhodobacter sphaeroides dimethyl sulfoxide reductase. J Biol Chem 275, 40202-40210.

Theg, S. M., Cline, K., Finazzi, G. \& Wollman, F. A. (2005). The energetics of the chloroplast Tat protein transport pathway revisited. Trends Plant Sci 10, 153-154.

Tokuda, H. \& Matsuyama, S. (2004). Sorting of lipoproteins to the outer membrane in E. coli. Biochim Biophys Acta 1693, 5-13.

Tranier, S., Mortier-Barriere, I., Ilbert, M., Birck, C., lobbi-Nivol, C., Mejean, V. \& Samama, J.-P. (2002). Characterization and multiple molecular forms of TorD from Shewanella massilia, the putative chaperone of the molybdoenzyme TorA. Protein Sci 11, 2148-2157. 
Tranier, S., lobbi-Nivol, C., Birck, C., Ilbert, M., Mortier-Barriere, I., Mejean, V. \& Samama, J.-P. (2003). A novel protein fold and extreme domain swapping in the dimeric TorD chaperone from Shewanella massilia. Structure 11, 165-174.

Truglio, J. J., Theis, K., Leimkühler, S., Rappa, R., Rajagopalan, K. V. \& Kisker, C. (2002). Crystal structures of the active and alloxanthineinhibited forms of xanthine dehydrogenase from Rhodobacter capsulatus. Structure 10, 115-125.

Turner, R. J., Papish, A. L. \& Sargent, F. (2004). Sequence analysis of bacterial redox enzyme maturation proteins (REMPs). Can J Microbiol 50, 225-238.

Vandeputte-Rutten, L., Kramer, R. A., Kroon, J., Dekker, N., Egmond, M. R. \& Gros, P. (2001). Crystal structure of the outer membrane protease OmpT from Escherichia coli suggests a novel catalytic site. EMBO J 20, 5033-5039.

van Dongen, W., Hagen, W., van den Berg, W. \& Veeger, C. (1988). Evidence for an unusual mechanism of membrane translocation of the periplasmic hydrogenase of Desulfovibrio vulgaris (Hildenborough), as derived from expression in Escherichia coli. FEMS Microbiol Lett 50, 5-9.

van Keulen, G., Alderson, J., White, J. \& Sawers, R. G. (2005). Nitrate respiration in the actinomycete Streptomyces coelicolor. Biochem Soc Trans 33, 210-212.

Vergnes, A., Pommier, J., Toci, R., Blasco, F., Giordano, G. \& Magalon, A. (2006). NarJ chaperone binds on two distinct sites of the aponitrate reductase of Escherichia coli to coordinate molybdenum cofactor insertion and assembly. J Biol Chem 281, 2170-2176.

Voelker, R. \& Barkan, A. (1995). Two nuclear mutations disrupt distinct pathways for targeting proteins to the chloroplast thylakoid. EMBO J 14, 3905-3914.

von Rozycki, T., Yen, M. R., Lende, E. E. \& Saier, M. H., Jr (2004). The YedZ family: possible heme binding proteins that can be fused to transporters and electron carriers. J Mol Microbiol Biotechnol 8, 129-140.

Vrontou, E. \& Economou, A. (2004). Structure and function of SecA, the preprotein translocase nanomotor. Biochim Biophys Acta 694, 67-80.

Walker, J. E., Saraste, M., Runswick, M. J. \& Gay, N. J. (1982). Distantly related sequences in the $\alpha$ - and $\beta$-subunits of ATP synthase, myosin, kinases and other ATP-requiring enzymes and a common nucleotide binding fold. EMBO J 1, 945-951.
Weiner, J. H., Bilous, P. T., Shaw, G. M., Lubitz, S. P., Frost, L., Thomas, G. H., Cole, J. A. \& Turner, R. J. (1998). A novel and ubiquitous system for membrane targeting and secretion of cofactorcontaining proteins. Cell 93, 93-101.

Widdick, D. A., Dilks, K., Chandra, G., Bottrill, A., Naldrett, M., Pohlschröder, M. \& Palmer, T. (2006). The twin-arginine translocation pathway is a major route of protein export in Streptomyces coelicolor. Proc Natl Acad Sci U S A 103, 17927-17932.

Winstone, T. L., Workentine, M. L., Sarfo, K. J., Binding, A. J., Haslam, B. D. \& Turner, R. J. (2006). Physical nature of signal peptide binding to DmsD. Arch Biochem Biophys 455, 89-97.

Wu, L.-F., Chanal, A. \& Rodrigue, A. (2000). Membrane targeting and translocation of bacterial hydrogenases. Arch Microbiol 173, 319-324.

Xi, H., Schneider, B. L. \& Reitzer, L. (2000). Purine catabolism in Escherichia coli and function of xanthine dehydrogenase in purine salvage. J Bacteriol 182, 5332-5341.

Yakunin, A. F., Proudfoot, M., Kuznetsova, E., Savchenko, A., Brown, G., Arrowsmith, C. H. \& Edwards, A. M. (2004). The HD domain of the Escherichia coli tRNA nucleotidyltransferase has $2^{\prime}, 3^{\prime}$ cyclic phosphodiesterase, $2^{\prime}$-nucleotidase, and phosphatase activities. J Biol Chem 279, 36819-36827.

Yamagata, A., Kakuta, Y., Masui, R. \& Fukuyama, K. (2002). The crystal structure of exonuclease RecJ bound to $\mathrm{Mn}^{2+}$ ion suggests how its characteristic motifs are involved in exonuclease activity. Proc Natl Acad Sci U S A 99, 5908-5912.

Yates, M. G., de Souza, E. M. \& Kahindi, J. H. (1997). Oxygen, hydrogen and nitrogen fixation in Azotobacter. Soil Biol Biochem 29, 863-869.

Yoshimatsu, K., Araya, O. \& Fujiwara, T. (2007). Haloarcula marismortui cytochrome $b-561$ is encoded by the narC gene in the dissimilatory nitrate reductase operon. Extremophiles 11, 41-47.

Zafra, O., Cava, F., Blasco, F., Magalon, A. \& Berenguer, J. (2005). Membrane-associated maturation of the heterotetrameric nitrate reductase of Thermus thermophilus. J Bacteriol 187, 3990-3996.

Zajicek, R. S., Allen, J. W., Cartron, M. L., Richardson, D. J. \& Ferguson, S. J. (2004). Paracoccus pantotrophus NapC can reductively activate cytochrome $c d_{1}$ nitrite reductase. FEBS Lett $565,48-52$. 